\title{
Assessment of potential hydrological climate change impacts in the Kastoria basin (Western Macedonia, Greece) using EURO- CORDEX regional climate models
}

\author{
Voulanas D. ${ }^{1,2 *}$, Theodossiou N. ${ }^{3}$ and Hatzigiannakis E. ${ }^{2}$ \\ ${ }^{1}$ Lab of Engineering Geology and Hydrogeology, Department of Geology, Aristotle University of Thessaloniki, Thessaloniki 54635, \\ Greece \\ ${ }^{2}$ Soil and Water Resources Institute, ELGO-DEMETER (ex NAGREF), Sindos 57400, Greece \\ ${ }^{3}$ Division of Hydraulics and Environmental Engineering, Department of Civil Engineering, Aristotle University of Thessaloniki, \\ Thessaloniki 54635, Greece \\ Received: 21/09/2020, Accepted: 12/01/2021, Available online: 03/02/2021 \\ *to whom all correspondence should be addressed: e-mail: dvoulanas@yahoo.com \\ https://doi.org/10.30955/gnj.003444
}

\section{Graphical abstract}

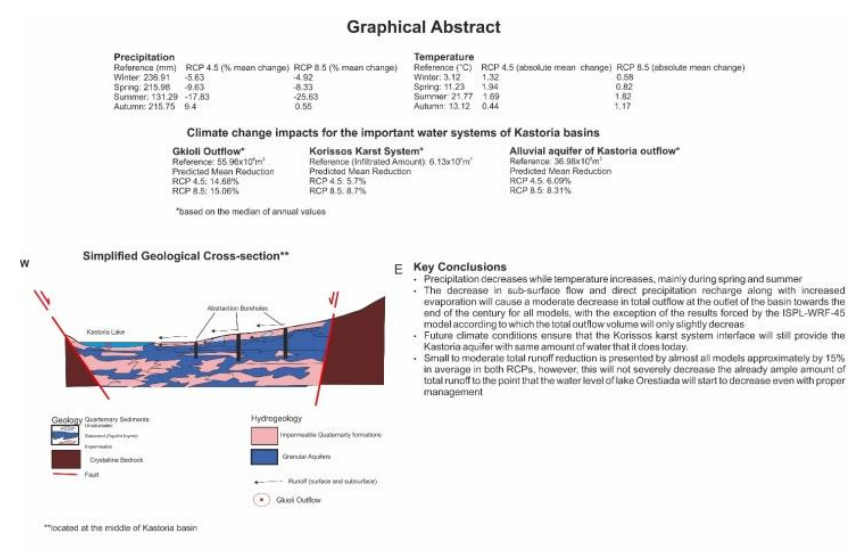

\section{Abstract}

The Mediterranean region is expected to present reduced availability of water resources due to climate change. This study aims to assess the potential hydrological responses to climate change in the Kastoria basin (Western Macedonia, Northern Greece) for the period 2019-2078. Climate projections from eight regional climate models from EURO-CORDEX were bias-adjusted using the linear scaling method. The bias-adjusted climate data were used to force the FeFLOW hydrological model to predict the discharge of the Kastoria aquifer towards lake Orestiada along with the projected groundwater level distribution. Precipitation (temperature) shows a tendency to decrease (increase) mainly in late spring to early autumn while increase (decrease) in the other seasons. Moreover, results indicate a significant increase in temperature and a slight decrease in precipitation towards 2078, while the predicted groundwater level of Kastoria aquifer will reduce slightly. However, the future hydrological behavior of the basin indicates a substantial reduction by approximately $15 \%$ of total water yield towards the end of the century.

Keywords: FeFLOW, water balance, Kastoria aquifer; groundwater flow model; climate change; EURO-CORDEX.

\section{Introduction}

Global climate change affects the water resources by altering the natural processes in Earth's ecosystem and thus impacts the water availability ( $X u$ and Singh, 2004). The Mediterranean region, referred to as one of the planet's hot spot (Giorgi, 2006), is expected to face two major water resources management challenges: increasing water stress, due to reduction in precipitation and increase in temperature, with fewer wet days and drier summers, and an increasing risk of flooding (Tolika et al., 2012). While climate change impact assessment studies regarding water resources across the Mediterranean region have been conducted in adequate numbers (i.e Hundecha et al., 2020; Krysanova et al., 2017) they have been conducted for large river basins (Lespinas et al., 2010). However, in Greece such studies are fairly limited (Panagopoulos et al., 2016; Pisinaras, 2016). According to MED EUWI Secretariat 2008, there is a widely acknowledged need for relatively small-scale impact research at regional and even local level. This is particularly true for the Mediterranean region and Greece which are dominated by relatively small basins. Smallscale impact research would ensure assessment of climate change impacts on water resources at higher resolution and assist further in the installation of mitigation measures.

Local climate change impact assessments require data in a high spatial resolution; hence imposing the use of regional climate models (RCMs). Many impact assessments require climate observations due to the fact that they are highly sensitive to fine-scale climate variations. This is especially true for complex topography regions, coastal or island 
locations, and in highly heterogeneous land-cover regions (Christensen and Christensen, 2007). In addition, Teutschbein \& Seibert (2010) suggest that using an ensemble of RCMs should quantify better the projected uncertainty than using a single RCM. A large ensemble of RCMs, such as those provided by among others the EUROCORDEX (Gobiet and Jacob, 2011) and MEDCORDEX (Ruti et al., 2016) projects, is available to provide model outputs for basin-scale studies. However, their outputs are often prone to strong systematic biases.

Bias-adjustment is usually applied to RCM outputs as climate models often provide biased representations of observed times series due to systematic errors caused by imperfect conceptualization, discretization, regional averaging within grid cells, difference between model orography and actual elevation and those inherited from global circulation models (Ehret et al., 2012; Teutschbein and Seibert, 2010, 2013). Typical examples of biases are the occurrence of too many wet days to those observed with low-intensity rain or incorrect estimation of extreme temperature (Ines and Hansen, 2006). Such biases in RCMsimulated variables can result to, for example, unrealistic hydrological simulations of river runoff, which is highly sensitive parameter (Bergstrom et al., 2001). This generally necessitates the adjustment of their outputs to remove the systematic biases stating that the need for bias adjustment adds significantly to uncertainties in modelling climate change impacts (Teutschbein and Seibert, 2010). As summarized and discussed by Ehret et al. (2012), among many researchers, there are several problematic aspects related to bias adjustment methods. Bias adjustment methods often impair the advantages of circulation models by altering spatiotemporal field consistency, relations among variables and by violating conservation principles. Also, they largely neglect feedback mechanisms, and it is unclear whether bias adjustment methods are time-invariant under climate change conditions. Applying bias adjustment increases agreement of GCM/RCM with observations and therefore reduces the uncertainty range of simulations and predictions, often without providing a satisfactory physical justification. This rather hides than reduces uncertainty, which may lead to avoidable forejudging by end users and decision makers.

Many studies have focused on the Kastoria basin, from different scientific points of view. Most of these studies often employ certain simplifications due to the limited availability of data. Studies that deal with hydrology usually study lake Orestiada directly. For example, Sakkas and Hrissanthou (2002) studied analytically the water balance of the lake while Demertzi et al. (2019) focused on the future condition of the water balance of lake Orestiada for the period 2061-2080 by modifying BrachtFlyrmethod. The latter study used the mean monthly GCM outputs of WorldClim v.1 database, which are interpolated surfaces of a finer resolution than the original resolution of GCMs. However, due to the low station density at certain regions the interpolated surfaces do not capture the variation that may occur, particularly in terms of precipitation in mountainous areas (Hijmans et al., 2005). Also, the use of one future period does not allow for a temporal analysis and therefore for an assessment of the future evolution of the water balance of the lake. Only one study, in the past, has analyzed the hydrological behavior of all important water systems found at Kastoria basin (Vafeiadis, 1983).

The aim of this study is to determine and assess the watershed scale climate change impact in conjunction with human-induced actions on the major water balance components of Kastoria basin using downscaled temperature and precipitation data derived from eight RCMs of the EURO-CORDEX project under two RCP scenarios (i.e. four RCMs under RCP 4.5 and four RCMs under RCP 8.5). Three 20-year long sub-periods of projected period 2019-2078 were used to allow for a temporal evaluation of the water resources for each system. A groundwater FeFLOW model was used to simulate the sub-surface flow of the basin while the rest of the hydrological components were calculated analytically based on previous research. This procedure aims to better approximate the hydrological processes of the basin by taking into account the hydrological characteristics of each of the basin's water bearing formations (Krysanova et al., 2018). It was calibrated using long term hydraulic head data and stochastic methods. The future climate and the hydrological behavior of the important water systems of the basin were explored on a seasonal basis for the former and on annual basis for the latter.

\section{Study area description}

Kastoria basin is a relatively small basin found in Western Macedonia, Northern Greece (between 40.425 $40.645^{\circ} \mathrm{N}$ and $21.225^{\circ}-21.475^{\circ} \mathrm{E}$ ) and is characterized predominately by mountainous topography with elevation ranging from 620 to $2000 m$ a.m.s.l (Figure 1). The mountainous topography which constitutes most part of the basin represents physical boundaries that cause variability in precipitation and temperature. The lithology of basin consists of metamorphic rocks, alluvial formations, karst limestones and semi-metamorphosed rocks. The land cover in the basin consists of by forested areas $(29 \%)$, pasture (44\%), agricultural land (24\%) and urban land use areas (3\%). The rest of the basin is occupied by the lake Orestiada (Vafeiadis, 1983).

Lake Orestiada exists in the center of the basin and covers an area of $33 \mathrm{~km}^{2}$ (10.5\% of the basin's total area). It has a mean depth of $5 \mathrm{~m}$ and its maximum of $9.6 \mathrm{~m}$ is found at south part of its body. Total runoff of the basin goes directly into the lake (Vafeiadis, 1983). This makes the water balance of the lake a direct reflection of the water regime of the entire basin. Sub-surface runoff comes mainly from the aquifer of Kastoria (Figure 1) while surface runoff is constituted by several streams (Figure 1), whose discharge comes only from extreme precipitation events with the exception of the Xiropotamos stream. The Xiropotamos stream presents an almost permanent flow (Vafeiadis, 1983). The lake is selectively drained by the 
Municipality of Kastoria through the Gkioli stream found at the south part of the basin due to the fact that the water level of the lake must be maintained between $+630.27 \mathrm{~m}$ and $+628.8 \mathrm{~m}$ a.m.s.I as suggested by the Water Resources Management Plans for Water District GR09.
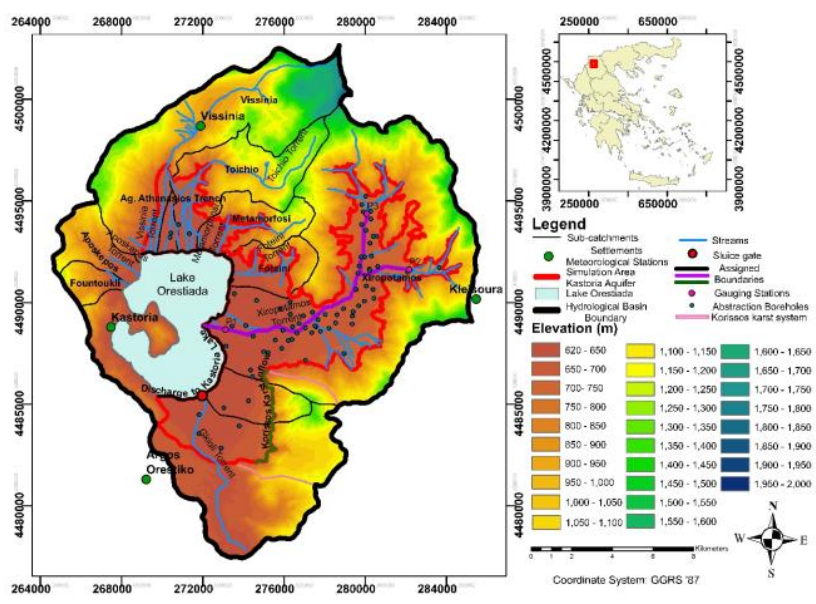

Figure 1 Elevation map, positions of meteorological stations, sub-catchments (adapted from Tolikas and Mylopoulos, 2000), abstraction boreholes and assigned boundaries conditions

The most significant water systems of the basin are the Kastoria alluvial aquifer system, the Korissos karst system to a lesser extent and lake Orestiada (Figure 1). The Kastoria alluvial aquifer constitutes the major source of water for irrigation needs. The last decades the agricultural activities, which is the major groundwater sink, have resulted in the construction of more than 78 main groundwater wells, at the body of the aquifer, used for the irrigation needs (Figure 1). Twenty of those belong the public irrigation network that cover most of the irrigation needs (Figure S1). These are the deepest boreholes and create a relatively large depression cone during pumping, due to their relatively close proximity to each other. The aquifer recharges mainly from precipitation and the lateral inflow that the surrounding formations provide. The Korissos karst system provides such an inflow to the southern part of the aquifer while the tectonized metamorphic rocks provide a similar influx to the rest of the aquifer. The alluvial aquifer of Kastoria located at the central and eastern part of the basin was considered for the FeFLOW model along with the Xiropotamos stream. The aquifer covers an area of approximately $77 \mathrm{~km}^{2}$ (nearly $24 \%$ of the Kastoria basin) with elevation ranging from 620 to $950 \mathrm{~m}$ a.m.s.I (Figure 1).

The climate of the area is characterized by sub-humid with severe winter with precipitation occurring mostly from autumn to spring season (Mavromattis, 1980). Maximum temperatures occur during the dry summer months, whereas the lowest are in the cold winter months. A considerable annual variability in temperature exists in the region. Sometimes the temperature drops below $0^{\circ} \mathrm{C}$ while rarely exceeds $35^{\circ} \mathrm{C}$. The average annual rainfall is $730 \mathrm{~mm}$. The plains of Kastoria basin receives relatively high amounts of rainfall while most of the rocky part of the basin receives a high amount of rainfall ranging from $750 \mathrm{~mm}$ to $1200 \mathrm{~mm}$.

\section{Materials and methods}

\subsection{Modelling procedure overview}

Climate change affects all water resources in a watershed, both surface and sub-surface. Surface water resources, e.g lake, are directly affected by any climatological change while sub-surface water resources show changes only after some time have passed, time lag, since the climatological change has happened. Despite their different response times both types of water resources are usually linked and inter-dependent. In this case, the most important water systems at the Kastoria basin are the Korissos karst system, the alluvial aquifer of Kastoria and lake Orestiada are in hydraulic communication, in that order, thus any change to each individual water storage will impact to their combined water storage.

RCM outputs were used for the assessment of future hydrologic regime of the important water systems in the selected watershed following a four-step procedure. First, the FeFLOW groundwater flow model of Kastoria alluvial aquifer was calibrated and validated using groundwater table measurements; second, the RCM outputs were selected from the available source and bias-adjustment was applied at each meteorological station based on the monthly data of the control period (1986-2005); third, the bias-adjusted RCM outputs were used to simulate the projected period as the continuation of reference simulation period (2000-2018) in order to assess the future hydrologic behavior of the aquifer as well as its discharge to the lake; and fourth, the rest of the future hydrological components of the basin's water balance were calculated analytically using water balance and the hydrological behavior of the important water systems of the basin was assessed.

The FeFLOW model was calibrated and validated with water table measurements taken at the end of the wet and dry period by Gianneli (2009) and IGME (2010) during the 2004-2007 and by Ministry of Agriculture 2013 during 2010-2011, respectively. The calibration procedure was implemented in two steps: first manually and then via stochastics methods offered by the Parameter ESTimation tool (Doherty, 2015). The selected RCMs were selected as worst-case scenarios, based on the improvement made by the selected bias-adjustment procedure and on their ability to represent the future climate change norms set for Greece, which are decrease in precipitation and increase in temperature, as for most countries surrounding the Mediterranean (Tolika et al., 2012; Zanis et al., 2015). The linear scaling method was selected for the bias-adjustment of the RCM outputs, due to it's simplicity and because it offers just as good as results with those offered by more complex methods when come to monthly scale (Shrestha et al., 2017). For the hydrological analysis of the future projection simulation runs, the model was set to run for the period of 2000-2018 as a reference period and $2019-2078$ as a projected period using the eight selected RCMs. The projected period was 
divided into three twenty year-long sub-periods. The water balance regime of each water system was then evaluated by constructing annual boxplots for each of the three sub-periods. A simplified flow chart shown in Figure 2 , describes the general procedures followed in this study.

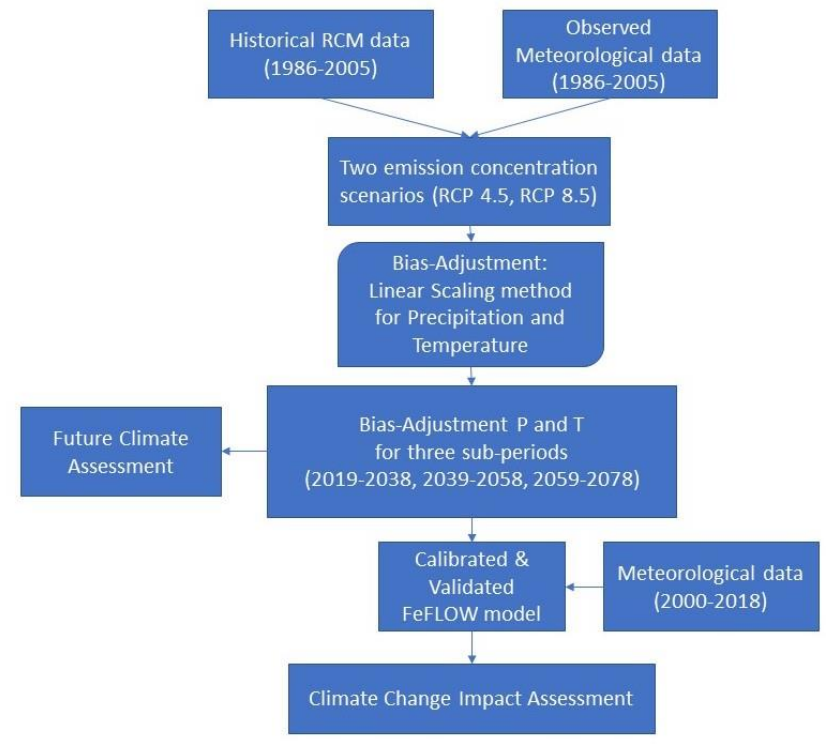

Figure 2 A flow chart of the general procedure used at this study

\subsection{RCMs outputs}

Dynamically downscaled air temperature and precipitation data were extracted from the future climate simulations of the EURO-CORDEX project. These simulations are based on three greenhouse gas concentration scenarios, which were adopted by the Intergovernmental panel for Climate Change at its 5th Assessment Report (AR5) in 2014. These representative concentration pathway (RCP) scenarios are the RCP 2.6, RCP 4.5 and RCP 8.5. All of the EURO-CORDEX RCMs are within the European window (between $\sim 27 \mathrm{~N}-\sim 72 \mathrm{~N}$, $\sim 22 \mathrm{~W}-\sim 45 \mathrm{E}$ ) at a grid spacing of about 12.5 or $25 \mathrm{~km}$ and are driven by several GCMs as their lateral boundary forcing fields, each one developed by a respective institute along with the corresponding RCM. This study used eight RCMs, four under RCP 4.5 and four under RCP 8.5 scenario. The summary of the selected models used in the present study is given in Table 1.

\subsection{Bias-adjustment}

The EURO-CORDEX-11 RCMs output represent daily values averaged within each grid cell at the model resolution $(\sim 12.5 \mathrm{~km})$ rather than local values that represent the

Table 1 Selected regional climate models for hydrological impact assessment in the Kastoria sub-basin

\begin{tabular}{|c|c|c|c|c|}
\hline RCP & Institution - GCM & RCMs & Hereafter Name & Reference \\
\hline \multirow{4}{*}{ RCP 4.5} & IPSL-IPSL-CM5A-MR & WRF331F & IPSL-WRF-45 & Skamarock et al. (2008) \\
\hline & MOHC-HadGEM2-ES & RCA4 & MOHC-RCA4-45 & Kupiainen et al. (2011) \\
\hline & MPI-M-MPI-ESM-LR & REMO2009 & MPI-R9-45 & Jacob et al. (2012) \\
\hline & MPI-M-MPI-ESM-LR & RCA4 & MPI-RCA4-45 & Kupiainen et al. (2011) \\
\hline \multirow{4}{*}{ RCP 8.5} & CNRM-CERFACS-CNRM-CM5 & CCLM4-8-17 & CNRM-CCLM4-85 & Rockel et al. (2008) \\
\hline & MPI-M-MPI-ESM-LR & CCLM4-8-17 & MPI-CCLM4-85 & Rockel et al. (2008) \\
\hline & MPI-M-MPI-ESM-LR & REMO2009 & MPI-R9-85 & Jacob et al. (2012) \\
\hline & MPI-M-MPI-ESM-LR & RCA4 & MPI-RCA4-85 & Kupiainen et al. (2011) \\
\hline
\end{tabular}

exact meteorological conditions. Nevertheless, the RCM outputs are prone to inherent systematic biases. According to Teutschbein and Seibert 2012, RCMs need to be "corrected" through a bias-adjustment method. Therefore, in order to use the RCM outputs in the adjustment was made on the extracted precipitation and temperature data.

A wide range of bias-adjustment methods are proposed and used. The simple methods alter the RCMs 'results as little as possible (Graham et al., 2007a). The pros and cons of the most widely applied simple bias-adjustment methods, namely the delta change and linear scaling, are presented by Teutschbein \& Seibert 2012. In this case, the linear scaling method were used. This method applies a constant correction factor that is estimated by the difference between the RCM simulations of the control period and the observations for each calendar month. Also, the variability of the adjusted data is more consistent with the original RCM data (Graham et al., 2007b). The observed precipitation and temperature at each station was compared to that of the nearest grid points of the RCM grid. This assumes that the grid points are as a single station in the watershed. The adjustment procedures adopted in this study are explained in the following equations:

$$
\begin{aligned}
& P^{*}=P \cdot \Delta P \\
& \Delta P=\left[\frac{\mu_{\mathrm{m}}\left(P_{\text {obs }}\right)}{\mu_{\mathrm{m}}\left(P_{\text {contr }}\right)}\right] \\
& T^{*}=T+\Delta T \\
& \Delta T=\mu_{\mathrm{m}}\left(T_{\text {obs }}\right)-\mu_{\mathrm{m}}\left(T_{\text {contr }}\right)
\end{aligned}
$$

where: $P^{*}$ is the bias-adjusted precipitation during the RCM scenario simulation; $T^{*}$ is the bias-adjusted temperature during the RCM scenario simulation; $P_{\text {obs }}$ is the observed precipitation at each meteorological station; $T_{\text {obs }}$ is the observed temperature at each meteorological station; $P_{\text {contr }}$ is precipitation of the RCM's control period; $T_{\text {contr }}$ is the temperature of the RCM's control period; $P$ is the raw RCM precipitation; $T$ is the raw RCM temperature; $\mu_{\mathrm{m}}$ is the mean within monthly interval. The subscripts obs and contr stands for the observed (or historical) and control period (1986-2005), respectively. hydrological modelling of the Kastoria basin further 


\subsection{Water balance model of lake Orestiada}

Study of the water balance of Lake Orestiada, which is considered as a reservoir of steady state conditions $(\Delta S=0)$, is necessary to understand the evolution of the Kastoria basin's water balance. For any given time, the water balance of a reservoir can be calculated by the following equation.

$$
\Delta S=V_{\text {IN }}-V_{\text {OUT }}
$$

where $V_{\text {IN }}$ and $V_{\text {OUt }}$ are the total inflow and outflow volumes, respectively. More specifically, inflows to the lake are the rainfall that falls to its surface $\left(V_{P}\right)$ and the surface runoff $\left(V_{R}\right)$ calculated using the surface runoff coefficient, $R=0.14$, estimated by Vafeiadis (1983). The sub-surface runoff $\left(V_{A}\right)$ values are produced from the FeFLOW model simulations. The setup of the FeFLOW model is described in a later section. Outflows from the lake include evaporation from its surface $\left(V_{E}\right)$ and discharge through the Gkioli stream to the Aliakmon River or the flow volume at the basin's outlet $\left(V_{G}\right)$. The $V_{E}$ values were received from Local Land Reclamation Institutes. Thus, $V_{\text {IN }}$ equals $V_{P}+V_{R}+V_{A}$ and $V_{\text {OUt }}$ equals $V_{E}+V_{G}$. Thus, the total outflow from the basin outlet $\left(V_{G}\right)$ can be calculated from the following equation.

$$
V_{G}=V_{P}+V_{R}+V_{A}-V_{E}
$$

Climate change impact can be reflected by assessing the deviation of the calculated $V_{G}$ value has from the value of about $56 \times 10^{6} \mathrm{~m}^{3}$ proposed by the current study, which is similar to those estimated and observed (the latter from nine years' worth of data), $57.1 \times 10^{6} \mathrm{~m}^{3}$ and $61.33 \times 10^{6} \mathrm{~m}^{3}$ by Sakkas (2002) and Vafeiadis (1983), respectively. For example, the closer the calculated $V_{\mathrm{G}}$ is to reference value the less the climate change impact to the water balance of the lake. In order to assess the impact of potential climate conditions on the water resources of these systems annual boxplots were constructed for each selected RCM and each sub-period. The reference period in this case, in contrast to the control period selected for the biasadjusted of the RCM data, is 2000-2018, due to the unavailability of prior observed water table level data for the Kastoria aquifer. This reference period partially overlaps with the control period of RCM data.

\subsection{Description of groundwater model}

In the present study, the FeFLOW groundwater flow modelling system (Diersch and Kolditz, 1998) was used for the simulation of aquifer response in the study area. The Kastoria alluvial aquifer system consists of fluvio-torrential alternating layers of permeable and impermeable material of generally small thickness and spatial extent. The aquifer has been characterized as unconfined at previous studies. This is explained by the existence of strong interconnections between permeable layers. The overall thickness of the aquifer exceeds $300 \mathrm{~m}$ in most places but only the first $100 \mathrm{~m}$ under being abstracted. Thus, the Kastoria aquifer was simulated as $100 \mathrm{~m}$ thick 2D unconfined aquifer. The aquifer is mainly affected by water sources and sinks vertically. A more detailed description of the hydrogeological system can be found in Vafeiadis (1983).

\subsubsection{Boundary conditions}

Boundary conditions govern the groundwater flow in an aquifer system. The boundary conditions of the Kastoria aquifer are illustrated in Figure 1. The Korissos karst system was not incorporated within the simulation domain, due to data unavailability, but rather as a Dirichlet boundary condition with flow constrains to limit the otherwise infinite flow. In addition, the Xiropotamos torrent was modelled as fluid flux boundary condition using mean seasonal values of transmission losses derived from monthly flow measurements taken by Gianneli (2009) during 2004-2007 at P1-P3 points. Finally, the outflow of the aquifer to the lake was modelled with a $629.535 \mathrm{~m}$ Dirichlet boundary condition constrained to estimated flow rates while the rest of the domain's perimeter was simulated as locally constrained fluid flux (Figure 1).

\subsubsection{Source/sink terms of groundwater}

In the model, the source/sink factors represent groundwater recharge and discharge from boreholes, all vertical to the model domain. At the Kastoria aquifer, the land-use pattern comprises of irrigation fields, pasture and urban areas. Groundwater abstractions are the sole source of irrigation water. Also, the groundwater level did not show any reduction since the 1980's and has a mean depth of approximately $2 \mathrm{~m}$. Precipitation and irrigation abstractions have the biggest effect on groundwater and are the dominant source/sink factor of the groundwater. The sink term is mainly irrigation. The irrigation season at the Kastoria basin starts in May and ends in September. The volume of irrigation needs, and therefore borehole abstraction water, were estimated using the HargreavesSamani equation (Hargreaves and Samani, 1985) for the reference evapotranspiration (ETo) multiplied with a crop factor $\left(K_{\mathrm{c}}\right)$ according to the crop type, the effective rainfall (Allen et al., 1998). Specific Kc values and crop types of the Kastoria basin were provided by the Greek Ministry of Agriculture (Koutsogiannis and Xanthopoulos, 1989) and Greek Payment Authority of Common Agricultural Policy Aid Schemes (OPEKEPE), respectively.

\subsubsection{Criteria for evaluation of the Kastoria aquifer groundwater model}

In this study, model performance was evaluated using a number of statistical scores. $R$ measures the degree of linear relation between two variables. RMSE provides a measure on the 'goodness of fit' in regard to groundwater levels, while $\mathrm{SD}_{\mathrm{r}}$ measures the spread of the hydraulic head residuals across the modelled domain. In addition, using the Student Distribution the statistical significance of simulated results was also assessed for both the calibration and validation periods (476 and 64 data points, respectively). 


$$
\begin{aligned}
& \mathrm{RMSE}=\sqrt{\frac{\sum_{i=1}^{n}\left(\mathrm{sim}_{i}-\mathrm{obs}_{i}\right)^{2}}{n}} \\
& R=\sqrt{\frac{\left[\sum_{i=1}^{n}\left(\mathrm{sim}_{i}-\overline{\operatorname{sim}}\right)\left(\mathrm{obs}_{i}-\overline{\mathrm{obs}}\right)\right]^{2}}{\sum_{i=1}^{n}\left(\operatorname{sim}_{i}-\overline{\operatorname{sim}}\right) \sum_{i=1}^{n}\left(\mathrm{obs}_{i}-\overline{\mathrm{obs}}\right)}} \\
& \mathrm{SD}_{\mathrm{r}}=\sqrt{\frac{n \sum \bar{h}_{\mathrm{r}}^{2}-\left(\sum \overline{h_{\mathrm{r}}}\right)}{n(n-1)}}
\end{aligned}
$$

where $h_{r}$ are the residual hydraulic heads, $\bar{h}_{r}$ is the mean value of the residual heads, obs are the observed hydraulic heads, $\overline{\text { obs }}$ is the mean value of the observed hydraulic heads, sim are the model calculated/simulated hydraulic heads, $\overline{\operatorname{sim}}$ in the mean value of the model calculated/simulated hydraulic heads and $n$ is the number of scores.

\section{Results and discussion}

\subsection{Groundwater flow model calibration}

Prior to the future groundwater level simulation, calibration was carried out using historical water table measurements for groundwater levels. The calibration was performed first through a trial and error procedure which included hydraulic conductivity, storativity, groundwater abstraction rates, groundwater recharge, inflow/outflow at the Xiropotamos torrent, outflow to the lake and the inflow from the Korissos karst aquifer system, and then in an automated fashion with the PEST tool for the same parameters but the last two. The values used in the models are calibrated according to the three statistical criteria stated above and the observed data for groundwater levels in 2004-2007. The model was verified with independent groundwater level data measured in 2010-2012. Overall, the yielded statistical criteria for the calibration period are RMSE of $0.63 \mathrm{~m}, \mathrm{SD}_{\mathrm{r}}$ of 0.45 , and $R$ of 0.94 while for the validation period of $1.08,0.64$ and 0.89 , respectively. This proves a strong correlation between observed and simulated hydraulic head distribution. Finally, the results of the calibration and validation periods were statistically significant at the 0.01 confidence level.

\subsection{Bias-adjustment performance}

The improvement made to the raw RCM data by the biasadjustment procedure was assessed by estimating Pearson's correlation coefficient, R, (Spearman's correlation coefficient for temperature, Rs), standard deviation, SD, and root mean squared difference, RMSD. With regard to raw $\mathrm{RCM}$ precipitation data, $\mathrm{R}$ ranged approximately between -0.12 and 0.14 for all selected RCMs while standard deviation ranged from 1.17 to 1.47 . The corresponding RMSD ranged between 2.02 and $2.36 \mathrm{~mm} /$ day. All selected RCMs were found to underestimate standard deviation compared to that of the observed data and, therefore, they indicate lower precipitation variation compared to that of the observed data. The bias-adjustment improved correlation coefficient as it was increased at every case by 0.3-0.29 units. Data points that are found closer to the "observed" point indicate better representation of observed patterns. With regard to raw RCM temperature data, Rs ranged between 0.92 and 0.95 , while standard deviation ranged between 6.71 and $7.83^{\circ} \mathrm{C}$. The RMSD ranged between 2.52 and $3^{\circ} \mathrm{C}$. Since correlation coefficient values of all selected $\mathrm{RCMs}$ in regard to raw temperature data are similar, the best performance is presented by those whose standard deviation is closer to that of the observed data. The biasadjustment improved correlation coefficient as it was slightly increased almost at every case. All RCMs were found to either underestimate or overestimate standard deviation and, therefore, they indicate higher temperature variation compared to the observed. A detailed form of the above metrics compiled for the raw and bias-adjusted RCMs precipitation and temperature data for the control period of 1986-2005 are presented in Tables S1 and S2, respectively. In addition, the mean absolute error (bias) over the control period before and after the bias-adjustment procedure is presented in the

\begin{tabular}{|c|c|c|c|c|c|c|c|c|c|}
\hline & MAE & $\begin{array}{c}\text { IPSL- } \\
\text { WRF-45 }\end{array}$ & $\begin{array}{l}\text { MOHC- } \\
\text { RCA4-45 }\end{array}$ & $\begin{array}{l}\text { MPI- } \\
\text { R9-45 }\end{array}$ & $\begin{array}{c}\text { MPI- } \\
\text { RCA4-45 }\end{array}$ & $\begin{array}{c}\text { CNRM- } \\
\text { CCLM4-85 }\end{array}$ & $\begin{array}{c}\text { MPI- } \\
\text { CCLM4-85 }\end{array}$ & $\begin{array}{l}\text { MPI- } \\
\text { R9-85 }\end{array}$ & $\begin{array}{c}\text { MPI- } \\
\text { RCA4-85 }\end{array}$ \\
\hline \multirow[t]{3}{*}{ Precipitation } & $\begin{array}{l}\text { Before Bias- } \\
\text { adjustment }\end{array}$ & 49 & 49 & 50 & 50 & 48 & 49 & 50 & 50 \\
\hline & $\begin{array}{c}\text { After Bias- } \\
\text { adjustment (in mm) }\end{array}$ & 31 & 36 & 34 & 33 & 30 & 31 & 34 & 33 \\
\hline & $\begin{array}{c}\text { After Bias- } \\
\text { adjustment (in \%) }\end{array}$ & -38 & -27 & -32 & -33 & -37 & -36 & -32 & -33 \\
\hline \multirow[t]{2}{*}{ Temperature } & $\begin{array}{l}\text { Before Bias- } \\
\text { adjustment }\end{array}$ & 1.92 & 1.16 & 1.15 & 1.11 & 1.51 & 1.22 & 1.15 & 1.11 \\
\hline & $\begin{array}{l}\text { After Bias- } \\
\text { adjustment (in }{ }^{\circ} \mathrm{C} \text { ) }\end{array}$ & 0.16 & 0.19 & 0.17 & 0.17 & 0.14 & 0.22 & 0.17 & 0.17 \\
\hline
\end{tabular}
following Table 2

Table 2 Mean Absolute Error (bias) over the control period for the Kastoria basin

\subsection{Quantification of climate change}

The monthly bias-adjustments factors and terms between the observed and simulated variables during the control period for each RCM were applied at each subperiod of the projected period for each station. However, those RCMs that use the same control data have the same correction factors. MOHC-RCA4-45 and MPI-RCA4-45/85 
show relatively larger bias as compared to the other models in regard to precipitation at the Kastoria station while at the Vissinia station all models have relatively the same bias factors. In respect to temperature, CNRMCCLM4-85 and MPI-CCLM4-85 are the most biased which present higher bias values during summer in contrast to the rest of the models whose stronger bias is found during the rest of the year. Also, low altitude stations present in relatively strong bias with a mean value of 1.35 , most of the higher values are found at the summer period while higher altitude stations present even greater bias in total with a mean value of 1.97 , where most models present their bulk bias during the winter period. This is a result of different lateral boundary forcing, parameterization, discretization and altitude difference between the model orography used at the RCMs and the actual altitude of each station and poses one source of uncertainty. Bias at RCMs outputs resulting from different GCM forcing were assessed in detail by Jacob et al. (2007) while biases and their relationship to orography for EURO-CORDEX were assessed in detail by Matiu et al. (2020), which included GCM and reanalysis driven EURO-CORDEX RCMs. For clarity, the monthly correction factors for two precipitation stations and one for temperature are shown in Table S2.

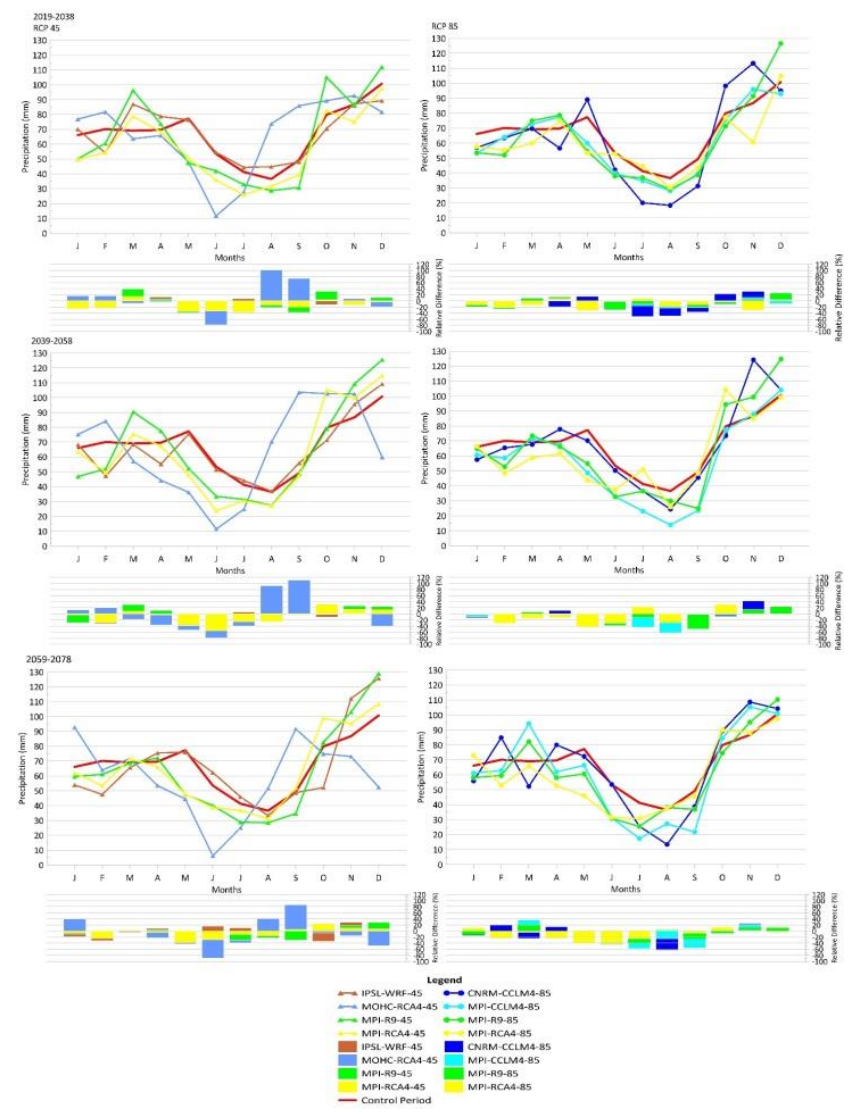

Figure 3. Spatially averaged monthly changes in precipitation over the control period in the Kastoria Basin for RCP 4.5 (left column) and RCP 8.5 (right column)

The monthly changes in the bias-adjustment results for the entire basin are presented in Table S4. From Figure 3 on seasonal average, the RCP 4.5 models showed decrease in precipitation mainly during winter, spring and summer ranging from 3.83 to $37.94 \%$, with decreasing trend towards the end of century - with the exception of model IPSL-WRF-45 which shows mainly increase by 0.47 to $12.03 \%$ during spring and summer - while during autumn mainly a moderate increase is shown ranging from 2.11 to $43.1 \%$ towards the end of century. The RCP 8.5 models showed decrease in precipitation during the whole year ranging from 0.09 to $46.83 \%$, with decreasing towards the end of century - with the exception of model CNRM-CCLM4-85 which shows increase by 9.69 to $12.74 \%$ during autumn. In regard to temperature, on seasonal average from Figure 4, the RCP 4.5 models showed increase during the whole year ranging from 0.77 to almost $2^{\circ} \mathrm{C}$ towards the end of the century - with the exception of model MOHC-RCA4-45 which shows decrease by 1.89 to $0.55^{\circ} \mathrm{C}$ during autumn. It also shows the largest increase of all the models by 0.06 to almost $6^{\circ} \mathrm{C}$ during the rest of the year, which is double that of the other RCP 4.5 models. The RCP 8.5 models showed a decrease ranging from 0.01 to almost $2^{\circ} \mathrm{C}$ mainly in winter and spring of the first sub-period while towards the end of the century they generally maintained an increase ranging from 0.34 to $4.17^{\circ} \mathrm{C}$ throughout the year.

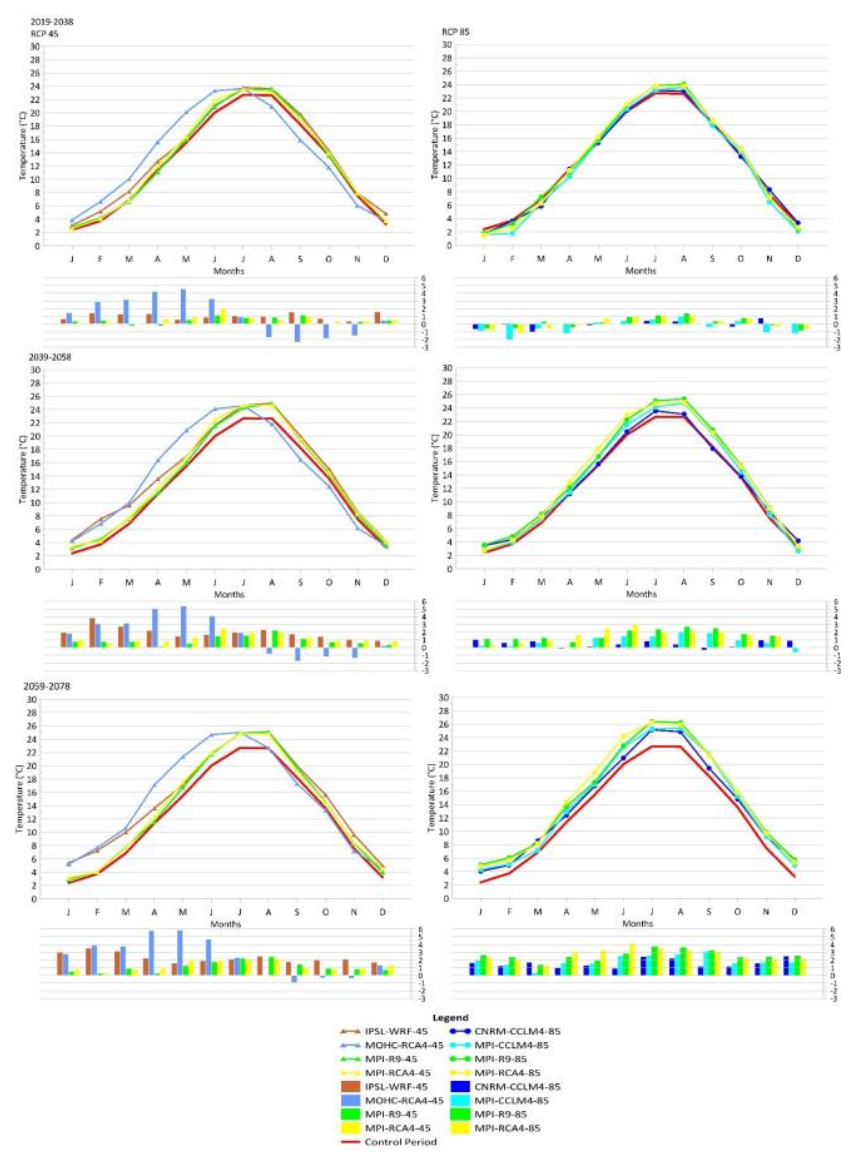

Figure 4. Spatially averaged monthly changes in temperature over the control period in the Kastoria Basin for RCP 4.5 (left column) and RCP 8.5 (right column)

4.4. Impact of potential future climate conditions on the important water systems of the Kastoria basin

4.4.1. Potential climate change impact at the Korissos karst system

Annual temporal variation of infiltrated water amount at Korissos karst system was assessed for the three sub- 
periods and compared to the median annual infiltrated amount of the reference period, which is $6.13 \times 10^{6} \mathrm{~m}^{3}$. The general point of the results illustrated in Figure 3 is that the infiltrated amount and therefore the stored water amount in the karst system is expected to be significantly decreased towards the year 2078.

When comparing the temporal change of annual infiltrated amount for each selected model, different trends are indicated. Most models yield slight increase during the first sub-period, in the range of 2.12 to $7.50 \%$ (the larger increase values are found at two of the models under RCP 4.5 namely IPSL-WRF-45 and MOHC-RCA4-45 while the increase the models under RCP 8.5 present is less than 5\%) in contrast to the other two sub-periods where slight to moderate decrease can be noticed ranging from 5.22 to $21.21 \%$, compared to the reference period. Comparing the mean annual values of the median of RCMs between each RCP, it is presented that there is a decrease of $1.63,10.69$ and $2.9 \%$, respectively for each sub-period for the RCP 4.5 models and decrease of 1.02, 9.14 and $15.66 \%$, respectively for each sub-period for the models of RCP 8.5. Model IPSL-WRF-45 constitute the exception of the general trend all the other models follow. It presents an almost constant increase. Model CNRMCCLM4-85 shows a slight increase only during the second sub-period despite showing a substantial decrease in the two other sub-periods but in total it does follow the decreasing trend of the other models. Consequently, the reduced precipitation will decrease the infiltrated amount at the Korissos karst system towards the end of the century.

Apart from the impact at the karst system storage, the impact on the lateral flow at the sub-surfaced interface between the karst system and the neighboring alluvial aquifer of Kastoria must also be assessed to maintain the already positive water balance of the aquifer as stated at the Water Resources Management Plans of Water District GR09. The interface provides a steady flow flux towards the aquifer at all times, as mentioned earlier. The corresponding water amount of this steady flux is approximately equal to $2.6 \times 10^{6} \mathrm{~m}^{3}$ per year, which is an amount far lower than the projected infiltrated water in the Korissos karst system. This ensures that the interface will recharge the aquifer with same amount of water that it does in the reference period.

\subsubsection{Potential climate change impact at the alluvial aquifer of Kastoria}

Annual temporal variation of the subsurface runoff received as inflow by the lake was assessed for the three sub-periods and compared to the median subsurface runoff of the reference period, which is $36.98 \times 10^{6} \mathrm{~m}^{3}$ and the results are illustrated in Figures 5 and 6 . The general point of the results is that subsurface runoff reduces throughout the projected period compared to the observed period, since the increase of the projected irrigation demand and reduced projected precipitation lowers the amount of outflow to the lake.
For most of the models the $\mathrm{Q}_{3}$ value is found below that of the reference data, which is an indicator of decrement in sub-surface runoff. Comparing the mean annual values of the median of RCMs between each RCP, it is presented that there is a decrease of $3.6,9.17$ and $5.5 \%$, respectively for each sub-period for RCP 4.5 and decrease of $8,8.71$ and $8.21 \%$, respectively for each sub-period for RCP 8.5 .

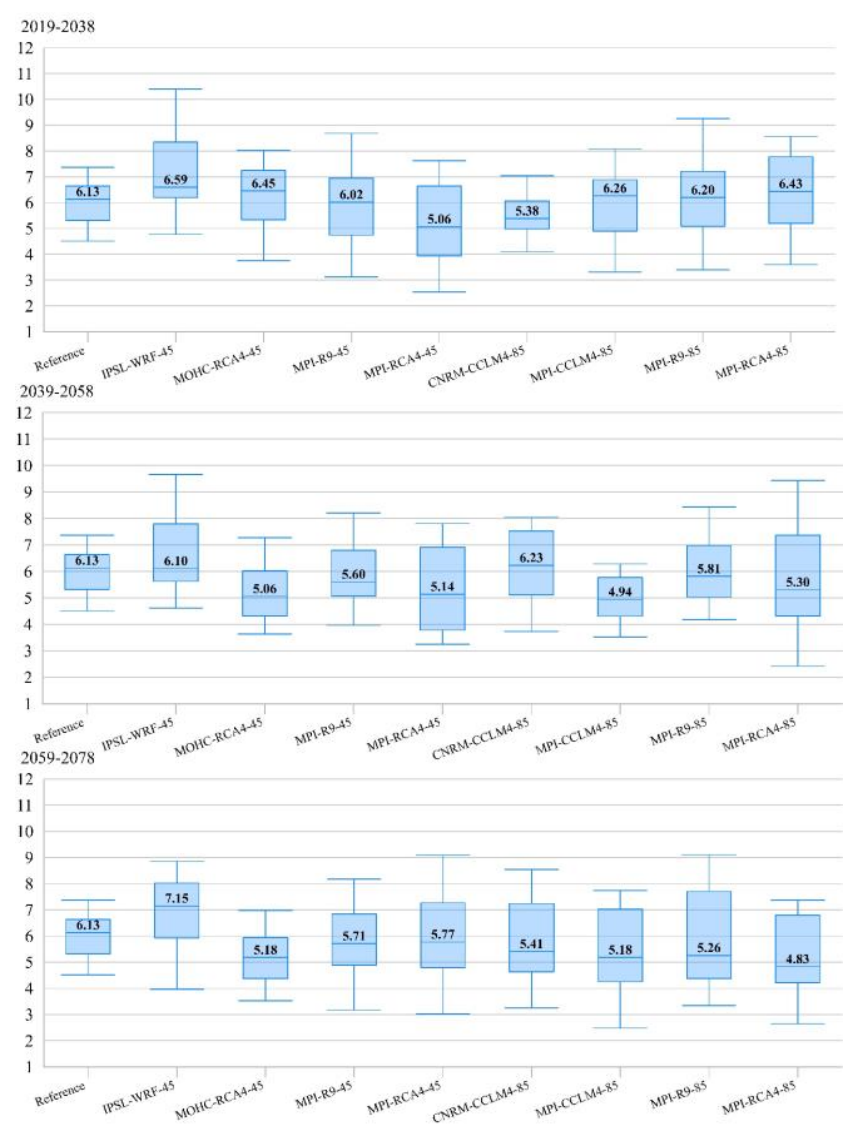

Figure 5 Box-plots of total annual infiltrated precipitation amount $\left(\times 10^{6} \mathrm{~m}^{3}\right)$ variation for the Korissos karst system forced by the eight selected RCMs for the periods 2019-2038, 20392058 and 2059-2078

When comparing the temporal change of the median value for each selected model, similar trends are indicated. All models present reduction of subsurface runoff in total during all sub-periods compared to the reference one. The strongest decrements are presented by models MOHC-RCA4-45 and MPI-RCA4-85, which are double the decrements of the other models. Model IPSLWRF-45 presents the weakest decrease of all the models, while it's the only model that presents any increase during the first sub-period despite being a slight one of $1.14 \%$. Also, models MPI-RCA4-45 and CNRM-CCLM4-85 present no climate change impact during the third and final subperiod. As a consequence, the increased irrigation water demand and reduced precipitation will decrease the water amount of subsurface runoff to the lake towards the end of the century for most models while, as mean annual values, between the models of each RCP a constant decrease is shown. Also, the intensification of the irrigation pumping results in a large depression cone 
located at the boreholes of the public irrigation network (Figure S1).

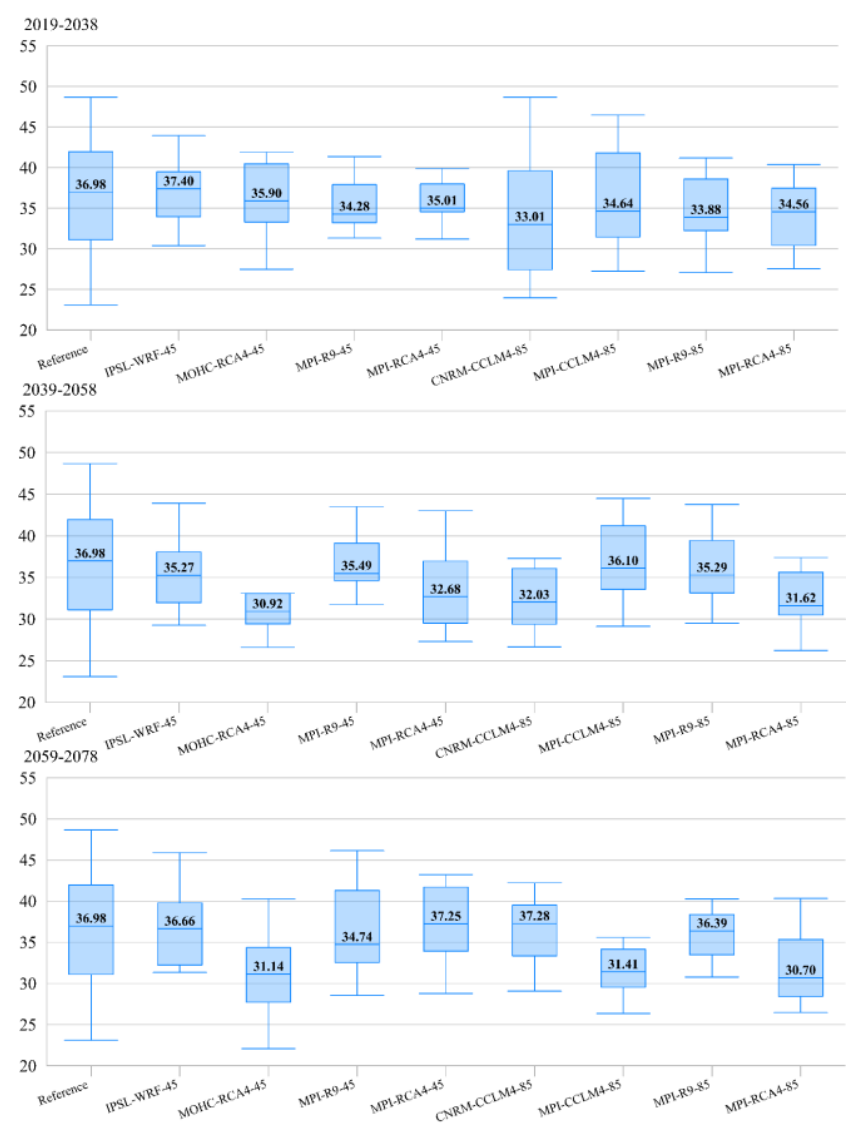

Figure 6 Box-plots of annual sub-surface runoff amount $\left(x 10^{6} \mathrm{~m}^{3}\right)$ variation at Kastoria sub-basin according to the simulated FeFLOW results forced by ten selected RCMs for the periods 2019-2038, 2039-2058 and 2059-2078

\subsubsection{Potential climate change impact in lake Orestiada outflow}

In order to evaluate the total outflow of the basin in response to climate change the rest of the water balance components of the lake were also forced by 60 year of bias corrected RCM outputs up to year 2078. Annual temporal variation of the outflow from Kastoria lake to Gkioli stream was assessed for the three sub-periods and compared to the median of total annual outflow of the reference period, which is $55.96 \times 10^{6} \mathrm{~m}^{3}$. Mean annual values of the water balance components of the lake are presented at Table S4. The general point of the results illustrated in Figure 7 is that this specific outflow reduces throughout the projected period compared to the observed period.

For most of the models the $Q_{3}$ value is found below that of the reference data, which also means a moderate decrease in total runoff. Comparing the mean annual values of the median of RCMs between each RCP, it is presented that there is decrease of $7.28,23.1$ and $13.66 \%$, respectively for each sub-period for RCP 4.5 and decrease of $8.48,16.22$ and $20.47 \%$, respectively for each subperiod for RCP 8.5.

When comparing the temporal change for each selected model, similar trends are indicated. All models present constant reduction of total runoff throughout the projected period compared to the reference one with the exception of the IPSL-WRF-45 model for the first and third sub-period as it shows an increase of 5.49 and $6.14 \%$, respectively while for the second shows a similar decrease to almost all of the other models. The strongest decrements are presented by models MOHC-RCA4- 45 and MPI-RCA4-85, which are double the decrements of the most other models. Consequently, reduced sub-surface runoff and reduced precipitation and increased evaporation will decrease the water amount of total runoff to the lake towards the end of the century for most models while between the models of each RCP a constant decrease is shown.

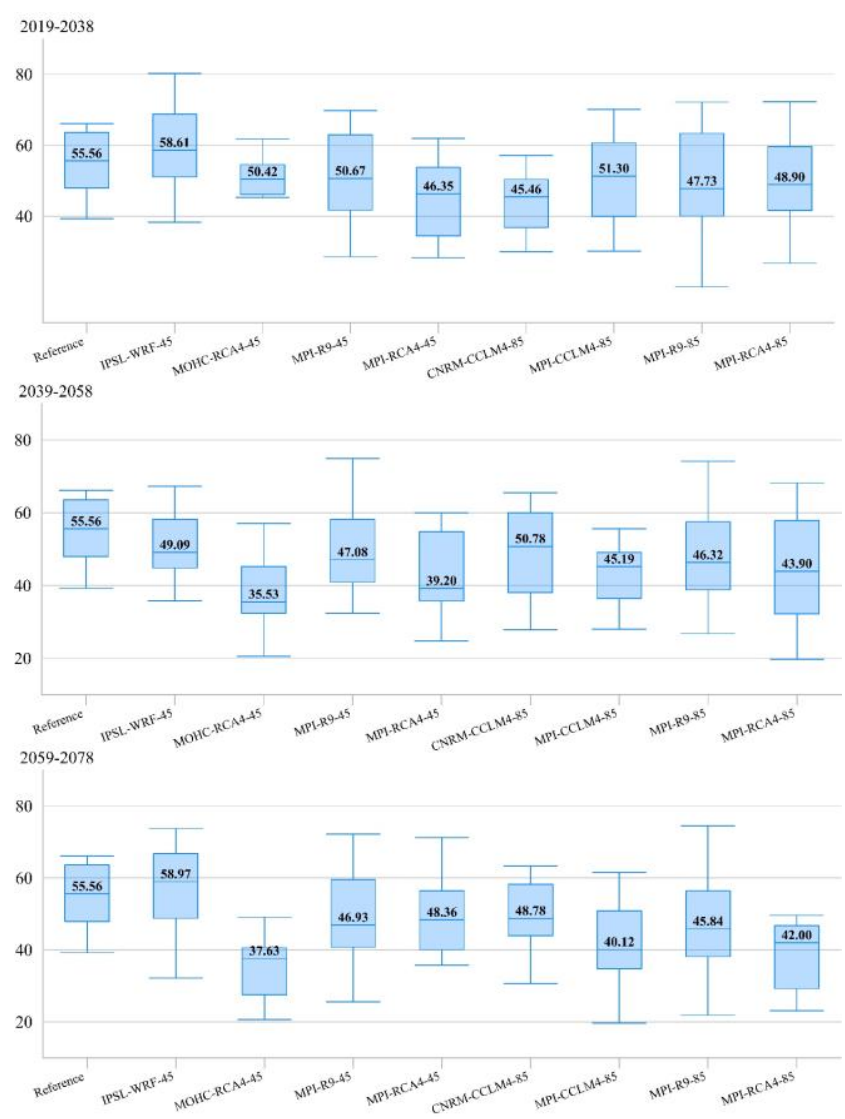

Figure 7 Box-plots of annual Gkioli stream flow, or total runoff, amount $\left(\times 10^{6} \mathrm{~m}^{3}\right)$ variation at Kastoria basin forced by eight selected RCMs for the periods 2019-2038, 2039-2058 and 20592078

\subsection{Discussion on uncertainty and further considerations}

In the present study, different FeFLOW simulations and water balance estimations of Lake Orestiada are presented, derived from eight RCMs forced by five different GCM lateral boundary conditions. However, various uncertainties exist in using RCMs for hydrological impact assessment that require further considerations. The major sources of uncertainties regarding future climate models are characterized as 'cascaded' (Giorgi, 2006) which are not necessarily additive or multiplicative but are inter-dependent (New and Hulme, 2000). This 'cascaded uncertainty', as it has been characterized, can be summarized into four groups (Xu et al., 2005). 
- The first is related to the choice of climate scenarios, in this case the EURO-CORDEX ensemble with the RCP 4.5 and RCP 8.5. Different scenarios can yield to different predictions of the hydrological component (Samaniego et al., 2017, Vetter et al., 2017; Pechlivanidis et al., 2018; Kiesel et al., 2020).

- The second, depending on the climatic gradient, as the choice of the forcing GCM-RCM as well as their number, which are generally considered to be the largest sources of uncertainty as concluded by many studies (e.g Dankers et al., 2014; Hattermann et al., 2017; Pechlivanidis et al., 2017; Samaniego et al., 2017; Vetter et al., 2017). Simulation biases are a combination of both GCM and RCM biases arising from a number of sources. There are general systematic biases in the ensemble set of EURO-CORDEX, and simulations have collective differences from observations. For example, the median of the simulations is generally colder and wetter than observed across Europe. Also, gridded observations suffer from large uncertainties due to the gridding scheme, station density, scale of variability, and measurement errors. Reanalysis datasets suffer from model biases or low spatial resolution (Vautard et al., 2020).

- The third source of uncertainty is related to the downscaling of large-scale climatology to regional-scale climatology appropriate for hydrological impact assessment. In this study, the linear scaling biasadjustment method was applied to dynamically downscaled RCMs of the EURO-CORDEX project. Teutschbein and Seibert, 2013, suggest the distribution mapping method as the best-performing correction method. However, in addition, they suggested that their results are yet to be validated at other catchments beyond of those they studied and other geographic regions that have different climate characteristics. In support of that, Shrestha et al. (2017) have come to the conclusion that the linear scaling approach is just as effective as quantile mapping when hydrological analysis comes at coarser temporal resolution of monthly scale.

- The fourth is related to the parameters and structure of hydrological and climate models and the validation of their results. For example, the inherent nature of hydrological modelling signifies that the model performance of a given hydrological model varies among sites, as comprehensive tuning and validation are often not possible due to lack of high-resolution and/or long-term time-series input data, comparably high computation costs, which processes each model includes in their modelling scheme and how good they can approximate it. This uncertainty, if not proper care is taken, and by interpreting the final results for further usage (Hattermann et al., 2017; Hundecha et al., 2020; Krysanova et al., 2018; Matiu et al., 2020; Vetter et al., 2017).

Quantitative determination of all the uncertainty factors is a long-standing research topic in climate change and climate change impact assessment. The propagation of individual uncertainty factors up to the final hydrologic impact study has been evaluated in various studies (e.g Hattermann et al., 2017; Kim et al., 2019; Lee et al., 2016). It is noted that emissions scenarios and climate models in general have their own limitations, as there the global socio-economic systems cannot be predicted and, therefore, the actual evolution of the climate in the future still remains in question. In future research, most of the above limitations will be alleviated, first, by conducting research dedicated to RCMs and bias-adjustment methods and, second, by setting up an elaborate integrated hydrological model of the entire basin, that still takes into account the hydrological characteristics of each formation of the Kastoria basin, fed with observed and remote sensing data in order to model delicate and important processes such as crop growth and snow melt.

\section{Conclusions}

This study presents the possible climate change impacts in precipitation, air temperature and in the water balance of the Kastoria basin close to the end of this century (2078) using the eight EURO-CORDEX RCMs. The linear scaling bias-adjustment method was applied to the RCM precipitation and temperature data. Precipitation decreases while temperature increases, mainly during spring and summer. The FeFLOW model of the Kastoria aquifer was successfully calibrated and validated based on observed water table level and weather data. The simulation results of the projected showed reduced subsurface flow towards the lake and a large drawdown at the boreholes of public irrigation network during the summer season that recovers during the rest of the year. This is due to the reduction in precipitation but mainly due to the increased irrigation pumping during the summer season. Future climate conditions ensure that the Korissos karst system interface will still provide the Kastoria aquifer with same amount of water that it does today. In regard to the water balance of the lake, the decrease in sub-surface flow and direct precipitation recharge along with increased evaporation will cause a moderate decrease in total outflow at the outlet of the basin towards the end of the century for all models, with the exception of the results forced by the ISPL-WRF-45 model according to which the total outflow volume will only slightly decrease. In total, small to moderate total runoff reduction is presented by almost all models approximately by $15 \%$ in average in both RCPs, however, this will not severely decrease the already ample amount of total runoff to the point that the water level of lake Orestiada will start to decrease even with proper management.

\section{Acknowledgments}

This study has been designed and conducted by Dimitrios Voulanas. N. Theodossiou and E. Hatzigiannakis supervised the study, which is based on research carried out in the framework of MSc Thesis entitled "Groundwater Flow Simulation using the FeFLOW Software, for the Alluvial Aquifer of Kastoria", Department of Geology, Lab of Engineering Geology and Hydrogeology (supervisor Prof. K. Voudouris) and the Soil and 
Water Institute, ELGO-DEMETER (ex NAGREF), Sindos 57400 Greece. The authors would like to thank DHI-WASY and Hydroelectric Generation Department of Public Power Corporation S.A. for providing the FeFLOW software and meteorological data for the Kastoria Basin, respectively, free of charge.

\section{References}

Allen R.G., Pereira L.S., Raes D., Smith M. and Ab W. (1998), Crop evapotranspiration - Guidelines for computing crop water requirements - FAO Irrigation and drainage paper 56, 1-15.

Christensen J.H. and Christensen O.B. (2010), A summary of the PRUDENCE model projections of changes in European climate by the end of this century, Climate Change, 81, 7-30.

Dankers R. et al. (2014), First look at changes in flood hazard in the inter-sectoral impact model intercomparison project ensemble, Proceedings of the National Academy of Sciences of the United States of America, 111, 3257-3261.

Demertzi K., Papadimos D., Aschonitis V. and Papamichail D.A. (2019), A simplistic approach for assessing hydroclimatic vulnerability of lakes and reservoirs with regulated superficial outflow, 6, 61 .

Diersch H.J.G. and Kolditz O. (1998), Coupled groundwater flow and transport: 2 . Thermohaline and 3D convection systems, Advances in Water Resources, 21(5), 401-425.

Doherty J. (2015) Calibration and Uncertainty Analysis for Complex Environmental Models, Watermark Numerical Computing, Brisbane, Australia. ISBN: 978-0-9943786-0-6.

Ehret U., Zehe E., Wulfmeyer V., Warrach-Sagi K., and Liebert J. (2012), HESS Opinions "Should we apply bias correction to global and regional climate model data?", Hydrology and Earth Systems Sciences, 16, 3391-3404, doi:10.5194/hess16-3391-2012.

European Environment Agency (2009), Water resources across Europe- confronting water scarcity and drought. EEA Report No 2/2009. http://www.eea.europa.eu/publicatio ns/water resources-across-europe. Accessed 2 Aug 2018.

Gianneli E. (2009), Hydrogeology investigation of basins of Greece: example from the basin of Agioi Anargiroi, Kastoria, Dissertation, Aristotle University of Thessaloniki. (in Greek).

Giorgi F. (2006) Climate change hot-spots, Geophysical Research Letters, 33, L08707.

Gobiet A. and Jacob D. (2011) The EURO-CORDEX-Initiative. WCRP Open Science Conference Denver, 24-28 Oct. 2011. Poster no. W108B.

Graham L.P., Andreasson J. and Carlsson B. (2007a) Assessing climate change impacts on hydrology from an ensemble of regional climate models, model scales and linking methodsa case study on the lule river basin, Climate Change, 81, 293307

Graham L.P., Hagemann S., Jaun S. and Beniston M. (2007b), On interpreting hydrological change from regional climate models, Climate Change, 81, 97-122

Hargreaves G.H. and Samani Z.A. (1985), Reference crop evapotranspiration from temperature, Transactions of the ASAE, 1(2), 96-99.

Hattermann F.F. et al. (2018), Sources of uncertainty in hydrological climate impact assessment: a cross-scale study, Environmental Research Letter, 13.
Hellenic Ministry for the Environment, Energy and Climate Change- Special Secretariat for Water (2014), Compilation of management plan for the river basins of Western Macedonia water district (GRO9)-management plan. Special Secretariat for Water, Athens. (in Greek).

Hijmans R.J., Cameron S.E., Parra J.L., Jones P.G., Jarvis A. (2005), Very high-resolution interpolated climate surfaces for global land areas, International Journal of Climatology 25, 19651978.

Hundecha Y., Arheimer B., Berg P., Capell R., Musuuza J., Pechlivanidis I., Photiadou C. (2020), Effect of model calibration strategy on climate projections of hydrological indicators at a continental scale, Climate Change.

Ines A.V.M. and Hansen J.W. (2006), Bias correction of daily GCM rainfall for crop simulation studies, Agricultural and Forest Meteorology, 138, 44-53.

Institute of Geology and Mining Research, Department of Water Resources and Environment (2010), Registration and evaluation of the Hydrogeological characteristics of Groundwater and Aquifers Systems, Subproject 3: Monitoring of water balances of the upper part of Aliakmonas river, Vermio, Ptolemaida (GR 09) (in Greek).

Jacob D., Bärring L., Christensen O.B. et al. (2007), An intercomparison of regional climate models for Europe: design of the experiments and model performance. Climate Change, 81, 31-52.

Kiesel J., Stanzel P., Kling H. et al. (2020), Streamflow-based evaluation of climate model sub-selection methods, Climatic Change. https://doi.org/10.1007/s10584-020-02854-8.

Kim Y., Ohn I., Lee J. and Kim Y. (2019), Generalizing uncertainty decomposition theory in climate change impact assessments, Journal of Hydrology X, 3, 100024.

Koutsogiannis and Xanthopoulos, Greek Ministry of Agriculture (1989), Determination of minimum and maximum crop water requirements for rational use of irrigation water, F16/6631, Athens, National Publishing Organization of Greece. (in Greek).

Krysanova V. et al. (2017), Intercomparison of regional-scale hydrological models in the present and future climate for 12 large river basins worldwide - A synthesis, Environmental Research Letters, 12, 105002.

Kupiainen M., Samuelsson P., Jones C., Jansson C., Willén U., Hansson U., Ullerstig A., Wang S. and Döscher R. (2011), Rossby Centre regional atmospheric model, RCA4. Rossby Centre Newsletter.

Lee J.-K., Kim Y.-O. and Kim Y. (2016), A new uncertainty analysis in the climate change impact assessment, International Journal of Climatology.

Lespinas F., Ludwig W. and Heussner S. (2010), Impact of recent climate change on the hydrology of coastal Mediterranean rivers in Southern France, Climatic Change, 99, 425-456.

Mavrommatis G. (1980a), The bioclimate of Greece. Climate and natural vegetation relations, bioclimatic maps, I.D.E.A, Athens (in Greek).

MED EUWI Secretariat (2008), Integrating the Climate Change Dimension into Water Resources Management in the Mediterranean, Euro-Mediterranean Ministerial Conference on Water, Dead Sea, Jordan, 29 October 2008.

Ministry of Agriculture and Food (2013) Chemical quality control of water supply (surface and underground) at basin river scale of Macedonia - Thrace and Thessalia (in Greek). 
New M. and Hulme M. (2000), Representing uncertainties in climate change scenarios: a Monte Carlo approach. Integr Assess 1.

OPEKEPE 2006-2018, Agricultural Data for Kastoria Basin.

Panagopoulos A., Arampatzis G., Tziritis E., Pisinaras V. and Herrmann F. (2016), Assessment of climate change impact in the hydrological regime of River Pinios Basin, central Greece, Desalination and Water Treatment, 57, 2256-2267

Pechlivanidis I.G., Arheimer B., Donnelly C., Hundecha Y., Huang S., Aich V. et al. (2017), Analysis of hydrological extremes at different hydro-climatic regimes under present and future conditions. Climate Change, 141(3), 467-481.

Pechlivanidis I.G., Arheimer B., Donnelly C., Hundecha Y., Huang S., Aich V. et al. (2017), Analysis of hydrological extremes at different hydro-climatic regimes under present and future conditions, Climatic Change, 141(3), 467-481.

Pechlivanidis I.G., Gupta H. and Bosshard T. (2018), An information theory approach to identifying a representative subset of hydro-climatic simulations for impact modelling studies, Water Resources Research, 54, 5422-5435.

Pisinaras V. (2016), Assessment of future climate change impacts in a mediterranean aquifer, Global Nest Journal, 18(1), 119130.

Rockel B., Will A. and Hense A. (eds.) (2008), Special issue regional climate modelling with COSMO-CLM (CCLM), Meteorologische Zeitschrift, 17(4), 9.

Ruti P., Somot S., Giorgi F., Dubois C. et al. (2016) MED-CORDEX initiative for mediterranean climate studies, Bulletin of the American Meteorological Society.

Sakkas J. and Hrissanthou V. (2002), Modelling of hydrologic balance in Kastoria Lake, 5th International Conference of the European Water Resources Association, Athens, Greece

Samaniego L., Kumar R., Breuer L., Chamorro A., Flörke M., Pechlivanidis I.G. et al. (2017), Propagation of forcing and model uncertainty into hydrological drought characteristics in a multi-model century-long experiment in continental river basins, Climate Change, 141(3), 435-449

Shrestha M., Acharya S.C. and Shrestha P.K. (2017), Bias correction of climate models for hydrological modelling - are simple methods still useful? Meteorological Applications, 24, 531-539.

Skamarock W.C., Klemp J.B., Dudhia J., Gill D.O., Duda DMBMG, Huang X.Y., Wang W. and Powers J.G. (2008), A description of the advanced research WRF version 3. NCAR Technical note 475 .

Teutschbein C. and Seibert J. (2010), Regional climate models for hydrological impact studies at the catchment scale: a review of recent modeling strategies, 7, 834-860.

Teutschbein C. and Seibert J. (2012). Bias correction of regional climate model simulations for hydrological climate change impact studies: review and evaluation of different methods, Journal of Hydrology, 456-457, 12-29

Teutschbein C. and Seibert J. (2013), Is bias correction of Regional Climate Model (RCM) simulations possible for nonstationary conditions? Hydrology and Earth Systems Science, 17, 5061-5077.

Tolika K., Zanis P. and Anagnostopoulou C. (2012), Regional climate change scenarios for Greece: Future temperature and Precipitation projections from Ensembles of RCMs, Global Nest Journal, 14(4), 407-421.
Tolikas D. and Mylopoulos G. (2000), Determination of discharges, sediments and water quality of the torrents of the catchment area of Kastoria lake. Trend investigations and application of alternative load reduction scenarios. Aristotle University of Thessaloniki, Department of Civil Engineering, Department of Hydraulics \& Environmental Engineering. Thessaloniki. (in Greek).

Vafeiadis P. (1983), Hydrogeological investigation of Kastoria basin, Dissertation, Aristotle University of Thessaloniki. (in Greek)

Vautard R. et al. (2020), Evaluation of the large EURO - CORDEX regional climate model ensemble. Journal of Geophysical Research: Atmospheres. doi:10.1029/2019jd032344.

Vetter T., Reinhardt J., Flörke M., van Griensven A., Hattermann F., Huang S. et al. (2017), Evaluation of sources of uncertainty in projected hydrological changes under climate change in 12 large-scale river basins, Climate Change, 141(3), 419-433.

Xu C.Y. and Singh V.P. (2004), Review on regional water resources assessment models under stationary and changing climate, Water Resources Management, 18(6), 591-612.

Xu C.Y., Widen E. and Halldin S. (2005), Modeling hydrological consequences of climate change - Progress and challenges, Advances in Atmospheric Sciences, 22(6), 789-797.

Zanis P., Katragkou E., Ntogras C., Marougianni G., Tsikerdekis A., Feidas H., Anadranistakis E. and Melas D. (2015), A transient high-resolution regional climate simulation for Greece for the period 1960-2100: Evaluation and future projections, Climate Research, 64, 123-140. 


\section{ANNEX}

\section{Supplementary material}

Table S1. Performance metrics or EUR-11 RCMs for the raw and bias-corrected (BC) results of precipitation

\begin{tabular}{|c|c|c|c|c|}
\hline Standard Deviation & Reference & Raw & BC & Change \\
\hline IPSL-WRF-45 & 1.7 & 1.17 & 1.51 & 0.34 \\
\hline MOHC-RCA4-45 & 1.7 & 1.47 & 1.75 & 0.28 \\
\hline MPI-R9-45 & 1.7 & 1.21 & 1.68 & 0.47 \\
\hline MPI-RCA4-45 & 1.7 & 1.46 & 1.58 & 0.12 \\
\hline CNRM-CCLM4-85 & 1.7 & 1.32 & 1.56 & 0.24 \\
\hline MPI-CCLM4-85 & 1.7 & 1.37 & 1.55 & 0.18 \\
\hline MPI-R9-85 & 1.7 & 1.21 & 1.68 & 0.47 \\
\hline MPI-RCA4-85 & 1.7 & 1.46 & 1.58 & 0.12 \\
\hline RMSD & Reference & Raw & BC & Change \\
\hline IPSL-WRF-45 & 0 & 2.13 & 2.04 & -0.08 \\
\hline MOHC-RCA4-45 & 0 & 2.15 & 2.31 & 0.15 \\
\hline MPI-R9-45 & 0 & 2.08 & 2.2 & 0.12 \\
\hline MPI-RCA4-45 & 0 & 2.15 & 2.12 & -0.03 \\
\hline CNRM-CCLM4-85 & 0 & 2.02 & 2 & -0.02 \\
\hline MPI-CCLM4-85 & 0 & 2.05 & 2.07 & 0.02 \\
\hline MPI-R9-85 & 0 & 2.08 & 2.2 & 0.12 \\
\hline MPI-RCA4-85 & 0 & 2.15 & 2.12 & -0.03 \\
\hline Pearson's Correlation Coefficient & Reference & Raw & BC & Change \\
\hline IPSL-WRF-45 & 1 & -0.05 & 0.18 & 0.23 \\
\hline MOHC-RCA4-45 & 1 & 0.09 & 0.11 & 0.03 \\
\hline MPI-R9-45 & 1 & 0.03 & 0.15 & 0.12 \\
\hline MPI-RCA4-45 & 1 & 0.08 & 0.18 & 0.09 \\
\hline CNRM-CCLM4-85 & 1 & 0.14 & 0.25 & 0.11 \\
\hline MPI-CCLM4-85 & 1 & 0.12 & 0.18 & 0.06 \\
\hline MPI-R9-85 & 1 & 0.03 & 0.15 & 0.12 \\
\hline MPI-RCA4-85 & 1 & 0.08 & 0.18 & 0.09 \\
\hline
\end{tabular}


Table S2. Performance metrics for EUR-11 RCMs for the raw and bias-corrected (BC) results of temperature

\begin{tabular}{|c|c|c|c|c|}
\hline Standard Deviation & Reference & Raw & $\mathrm{BC}$ & Change \\
\hline IPSL-WRF-45 & 7.45 & 7.02 & 7.44 & 0.42 \\
\hline MOHC-RCA4-45 & 7.45 & 7.69 & 7.41 & -0.28 \\
\hline MPI-R9-45 & 7.45 & 6.71 & 7.4 & 0.69 \\
\hline MPI-RCA4-45 & 7.45 & 7.19 & 7.41 & 0.22 \\
\hline CNRM-CCLM4-85 & 7.45 & 7.83 & 7.44 & -0.39 \\
\hline MPI-CCLM4-85 & 7.45 & 7.56 & 7.48 & -0.08 \\
\hline MPI-R9-85 & 7.45 & 6.71 & 7.4 & 0.69 \\
\hline MPI-RCA4-85 & 7.45 & 7.19 & 7.41 & 0.22 \\
\hline RMSD & Reference & Raw & $\mathrm{BC}$ & Change \\
\hline IPSL-WRF-45 & 0 & 2.95 & 2.54 & -0.41 \\
\hline MOHC-RCA4-45 & 0 & 2.63 & 2.44 & -0.19 \\
\hline MPI-R9-45 & 0 & 2.59 & 2.4 & -0.19 \\
\hline MPI-RCA4-45 & 0 & 2.58 & 2.44 & -0.15 \\
\hline CNRM-CCLM4-85 & 0 & 2.52 & 2.43 & -0.1 \\
\hline MPI-CCLM4-85 & 0 & 2.7 & 2.67 & -0.03 \\
\hline MPI-R9-85 & 0 & 2.59 & 2.4 & -0.19 \\
\hline MPI-RCA4-85 & 0 & 2.58 & 2.44 & -0.15 \\
\hline Spearman's Correlation Coefficient & Reference & Raw & BC & Change \\
\hline IPSL-WRF-45 & 1 & 0.93 & 0.94 & 0.01 \\
\hline MOHC-RCA4-45 & 1 & 0.94 & 0.94 & 0.01 \\
\hline MPI-R9-45 & 1 & 0.94 & 0.94 & 0 \\
\hline MPI-RCA4-45 & 1 & 0.93 & 0.93 & 0 \\
\hline CNRM-CCLM4-85 & 1 & 0.93 & 0.94 & 0.01 \\
\hline MPI-CCLM4-85 & 1 & 0.94 & 0.94 & 0.01 \\
\hline
\end{tabular}


Table S3. Bias correction factors used to modify the simulated climate variables at Kastoria sub-basin; A: precipitation, B:Temperature

\begin{tabular}{|c|c|c|c|c|c|c|c|c|c|c|c|c|}
\hline \multirow{3}{*}{ Kastoria Station } & & & & & & & & & & & & \\
\hline & \multicolumn{12}{|c|}{ Precipitation } \\
\hline & \multicolumn{12}{|c|}{ (relative correction factors) } \\
\hline RCM\Calendar Month & $\mathrm{J}$ & $\mathbf{F}$ & $M$ & $\mathbf{A}$ & $M$ & $\mathrm{~J}$ & $\mathrm{~J}$ & A & $\mathbf{S}$ & 0 & $\mathbf{N}$ & D \\
\hline IPSL-WRF-45 & 1.17 & 1.18 & 1.06 & 1.01 & 0.88 & 0.43 & 0.4 & 0.82 & 1.49 & 1.21 & 2.2 & 2.59 \\
\hline MOHC-RCA4-45 & 1.33 & 1.62 & 0.76 & 0.94 & 1.95 & 2.56 & 5.46 & 5.51 & 2.33 & 1.04 & 1.4 & 0.89 \\
\hline MPI-R9-45 & 0.59 & 0.82 & 0.85 & 0.64 & 0.55 & 0.5 & 0.94 & 0.81 & 0.84 & 1.27 & 1.36 & 1.54 \\
\hline MPI-RCA4-45 & 0.73 & 0.75 & 0.75 & 0.8 & 1.26 & 2.89 & 12 & 5.46 & 1.59 & 1.28 & 0.93 & 1.21 \\
\hline CNRM-CCLM4-85 & 0.63 & 0.84 & 0.57 & 0.75 & 0.9 & 0.54 & 0.83 & 0.78 & 0.68 & 0.96 & 1.28 & 1.12 \\
\hline MPI-CCLM4-85 & 0.49 & 0.72 & 0.73 & 0.68 & 0.8 & 0.94 & 1.59 & 0.91 & 0.89 & 0.75 & 0.98 & 0.98 \\
\hline MPI-R9-85 & 0.59 & 0.82 & 0.85 & 0.64 & 0.55 & 0.5 & 0.94 & 0.81 & 0.84 & 1.27 & 1.36 & 1.54 \\
\hline MPI-RCA4-85 & 0.73 & 0.75 & 0.75 & 0.8 & 1.26 & 2.89 & 12 & 5.46 & 1.59 & 1.28 & 0.93 & 1.21 \\
\hline Vissinia Station & $\mathbf{J}$ & $\mathbf{F}$ & $M$ & A & $M$ & $\mathrm{~J}$ & $\mathbf{J}$ & A & $S$ & 0 & $\mathbf{N}$ & D \\
\hline IPSL-WRF-45 & 2.19 & 2.08 & 1.98 & 1.61 & 1.17 & 0.51 & 0.51 & 1.35 & 2.27 & 2.64 & 3.19 & 4.08 \\
\hline MOHC-RCA4-45 & 2.35 & 2.61 & 1.41 & 1.01 & 1.03 & 0.51 & 1.5 & 2.24 & 1.2 & 1.32 & 1.88 & 1.4 \\
\hline MPI-R9-45 & 2.08 & 2.34 & 2.86 & 2.18 & 1.31 & 0.9 & 1.68 & 1.53 & 1.85 & 3.21 & 3.87 & 4.76 \\
\hline MPI-RCA4-45 & 1.42 & 1.35 & 1.21 & 0.92 & 0.81 & 0.82 & 1.65 & 1.45 & 1.18 & 1.92 & 1.46 & 1.92 \\
\hline CNRM-CCLM4-85 & 1.23 & 1.6 & 1.21 & 1.47 & 1.55 & 0.84 & 1.35 & 1.69 & 1.14 & 1.98 & 2.15 & 1.93 \\
\hline MPI-CCLM4-85 & 0.94 & 1.35 & 1.55 & 1.28 & 1.43 & 1.61 & 3.17 & 1.98 & 1.4 & 1.61 & 1.71 & 1.65 \\
\hline MPI-R9-85 & 2.08 & 2.34 & 2.86 & 2.18 & 1.31 & 0.9 & 1.68 & 1.53 & 1.85 & 3.21 & 3.87 & 4.76 \\
\hline MPI-RCA4-85 & 1.42 & 1.35 & 1.21 & 0.92 & 0.81 & 0.82 & 1.65 & 1.45 & 1.18 & 1.92 & 1.46 & 1.92 \\
\hline \multicolumn{13}{|l|}{ B } \\
\hline \multirow{2}{*}{ Kastoria Station } & \multicolumn{12}{|c|}{ Temperature } \\
\hline & \multicolumn{12}{|c|}{ (Absolute correction factors) } \\
\hline RCM\Calendar Month & J & $\mathbf{F}$ & $\mathbf{M}$ & A & M & $\mathbf{J}$ & J & A & $\mathbf{S}$ & 0 & $\mathbf{N}$ & D \\
\hline IPSL-WRF-45 & 0.72 & 2.29 & 3.3 & 5.18 & 4.66 & 4.46 & 2.54 & 1.9 & 1.43 & 2.45 & 1.07 & -0.04 \\
\hline MOHC-RCA4-45 & 0.63 & 1.67 & 1.81 & 3.74 & 1.77 & 0.41 & -0.2 & 0.65 & 1.15 & 2.97 & 0.87 & 0.35 \\
\hline MPI-R9-45 & -2.14 & -1.6 & -1 & 0.85 & 0.55 & 0.86 & 0.21 & -0.12 & -1.18 & -0.69 & -1.24 & -2.15 \\
\hline MPI-RCA4-45 & -0.05 & 0.47 & 1.11 & 3.37 & 2.32 & 1.26 & 0.36 & 1.07 & 1.28 & 2.02 & 0.92 & -0.09 \\
\hline CNRM-CCLM4-85 & 2.96 & 2.55 & 2.34 & 2.99 & 2.62 & 2.8 & 1.92 & 1.31 & 0.75 & 1.76 & 2.55 & 2.39 \\
\hline MPI-CCLM4-85 & 1.35 & 1.05 & 1 & 1.78 & 1.69 & 1.38 & 0.67 & 1.26 & 0.67 & 1.48 & 1.38 & 1.08 \\
\hline MPI-R9-85 & -2.14 & -1.6 & -1 & 0.85 & 0.55 & 0.86 & 0.21 & -0.12 & -1.18 & -0.69 & -1.24 & -2.15 \\
\hline MPI-RCA4-85 & -0.05 & 0.47 & 1.11 & 3.37 & 2.32 & 1.26 & 0.36 & 1.07 & 1.28 & 2.02 & 0.92 & -0.09 \\
\hline
\end{tabular}


Table S4. Monthly changes in precipitation in $\mathrm{mm}(\mathrm{A})$ and temperature in ${ }^{\circ} \mathrm{C}(\mathrm{B})$

A

\begin{tabular}{|c|c|c|c|c|c|c|c|c|c|c|c|c|}
\hline \multicolumn{13}{|l|}{ Precipitation } \\
\hline 2019-2038 & $\mathrm{J}$ & $\mathbf{F}$ & $M$ & A & $M$ & $\mathrm{~J}$ & $\mathrm{~J}$ & A & $\mathbf{S}$ & 0 & $\mathbf{N}$ & D \\
\hline Control & 66 & 70 & 69 & 70 & 77 & 53 & 41 & 37 & 49 & 80 & 87 & 101 \\
\hline IPSL-WRF-45 & 70 & 54 & 87 & 79 & 76 & 54 & 44 & 45 & 48 & 70 & 87 & 89 \\
\hline Relative Difference (\%) & 6.01 & -23 & 25.86 & 12.93 & -1.13 & 1.86 & 7.61 & 22.51 & -2.39 & -11.67 & 0.44 & -11.43 \\
\hline MOHC-RCA4-45 & 77 & 82 & 64 & 66 & 48 & 12 & 28 & 74 & 86 & 89 & 93 & 82 \\
\hline Relative Difference (\%) & 16.3 & 16.56 & -7.86 & -5.52 & -37.72 & -78.25 & -32.97 & 101.56 & 74.28 & 11.87 & 6.86 & -18.94 \\
\hline MPI-R9-45 & 50 & 61 & 96 & 74 & 47 & 42 & 33 & 29 & 31 & 105 & 86 & 112 \\
\hline Relative Difference (\%) & -24.3 & -13.68 & 39.3 & 5.79 & -38.73 & -21.42 & -20.41 & -21.36 & -37.43 & 31.69 & -0.8 & 11.18 \\
\hline MPI-RCA4-45 & 50 & 54 & 79 & 68 & 51 & 36 & 26 & 32 & 39 & 83 & 75 & 97 \\
\hline Relative Difference (\%) & -24.82 & -22.52 & 13.94 & -1.86 & -34.59 & -32.99 & -37.36 & -13.25 & -20.34 & 3.64 & -13.51 & -3.24 \\
\hline CNRM-CCLM4-85 & 57 & 63 & 70 & 57 & 89 & 42 & 20 & 18 & 31 & 98 & 113 & 95 \\
\hline Relative Difference (\%) & -13.87 & -9.58 & 0.84 & -18.75 & 15.16 & -21.22 & -51.39 & -49.78 & -36.5 & 23.06 & 30.68 & -5.73 \\
\hline MPI-CCLM4-85 & 53 & 64 & 73 & 77 & 60 & 40 & 35 & 28 & 39 & 76 & 96 & 93 \\
\hline Relative Difference (\%) & -19.51 & -8.63 & 5.25 & 11.13 & -22.4 & -25.49 & -15.75 & -23.34 & -19.77 & -5.23 & 10.57 & -7.72 \\
\hline MPI-R9-85 & 53 & 52 & 75 & 79 & 55 & 38 & 37 & 29 & 39 & 71 & 91 & 127 \\
\hline Relative Difference (\%) & -19.15 & -25.93 & 8.49 & 12.87 & -29.4 & -29.06 & -10.86 & -20.54 & -21.39 & -10.71 & 5.34 & 25.64 \\
\hline MPI-R9-85 & 58 & 55 & 60 & 75 & 53 & 53 & 45 & 30 & 43 & 77 & 61 & 105 \\
\hline Relative Difference (\%) & -12.83 & -21.18 & -13.43 & 7.26 & -31.04 & -1.8 & 7.99 & -16.98 & -11.86 & -3.49 & -30.12 & 4.03 \\
\hline 2039-2058 & $\mathrm{J}$ & $\mathbf{F}$ & $\mathbf{M}$ & $\mathbf{A}$ & $\mathbf{M}$ & $\mathrm{J}$ & $\mathrm{J}$ & A & $\mathrm{S}$ & 0 & $\mathbf{N}$ & D \\
\hline Control & 66 & 70 & 69 & 70 & 77 & 53 & 41 & 37 & 49 & 80 & 87 & 101 \\
\hline IPSL-WRF-45 & 68 & 47 & 68 & 55 & 75 & 51 & 44 & 37 & 56 & 71 & 96 & 109 \\
\hline Relative Difference (\%) & 3.32 & -32.7 & -1.09 & -20.63 & -2.35 & -3.81 & 6.88 & 0.93 & 13.78 & -10.68 & 10.17 & 8.35 \\
\hline MOHC-RCA4-45 & 75 & 84 & 57 & 44 & 36 & 11 & 25 & 70 & 104 & 103 & 102 & 60 \\
\hline Relative Difference (\%) & 13.85 & 20.04 & -17.23 & -36.44 & -53.08 & -78.53 & -39.74 & 92.18 & 110.49 & 28.64 & 18.16 & -40.58 \\
\hline MPI-R9-45 & 47 & 52 & 90 & 77 & 52 & 34 & 31 & 27 & 49 & 79 & 109 & 125 \\
\hline Relative Difference (\%) & -28.98 & -25.87 & 30.88 & 11.26 & -32.33 & -37.34 & -23.87 & -25.14 & -0.58 & -0.97 & 25.95 & 24.6 \\
\hline MPI-RCA4-45 & 63 & 50 & 75 & 67 & 48 & 24 & 31 & 27 & 47 & 105 & 100 & 115 \\
\hline Relative Difference (\%) & -4.03 & -29.17 & 9.16 & -3.19 & -38.04 & -55.42 & -25.87 & -26.01 & -3.7 & 31.74 & 15.13 & 13.94 \\
\hline CNRM-CCLM4-85 & 58 & 65 & 68 & 78 & 70 & 50 & 36 & 24 & 46 & 74 & 124 & 104 \\
\hline Relative Difference (\%) & -12.94 & -6.75 & -1.98 & 11.79 & -9.11 & -5.92 & -11.64 & -33.24 & -7.56 & -7.87 & 43.24 & 3.27 \\
\hline MPI-CCLM4-85 & 61 & 59 & 71 & 68 & 49 & 33 & 23 & 14 & 23 & 77 & 88 & 104 \\
\hline Relative Difference (\%) & -8.26 & -16.44 & 3.35 & -2.97 & -37.02 & -38.61 & -44.14 & -61.87 & -52.27 & -3.15 & 1.34 & 3.38 \\
\hline MPI-R9-85 & 65 & 53 & 73 & 66 & 55 & 33 & 36 & 30 & 25 & 94 & 99 & 125 \\
\hline Relative Difference (\%) & -1.83 & -24.72 & 6.33 & -4.96 & -29 & -38.81 & -11.68 & -18.1 & -49.38 & 18.31 & 14.56 & 23.83 \\
\hline MPI-RCA4-85 & 67 & 48 & 59 & 62 & 44 & 37 & 51 & 26 & 49 & 104 & 85 & 99 \\
\hline Relative Difference (\%) & 0.74 & -30.96 & -14.79 & -11.67 & -43.33 & -29.96 & 23.2 & -28.74 & -1.45 & 30.75 & -2.25 & -1.53 \\
\hline 2059-2078 & $\mathrm{J}$ & $F$ & $M$ & A & M & $\mathrm{J}$ & $\mathrm{J}$ & A & $S$ & 0 & $\mathbf{N}$ & D \\
\hline Control & 66 & 70 & 69 & 70 & 77 & 53 & 41 & 37 & 49 & 80 & 87 & 101 \\
\hline IPSL-WRF-45 & 54 & 47 & 66 & 75 & 76 & 62 & 46 & 33 & 49 & 52 & 112 & 126 \\
\hline
\end{tabular}




\begin{tabular}{|c|c|c|c|c|c|c|c|c|c|c|c|c|}
\hline Relative Difference (\%) & -18.42 & -32.29 & -5.08 & 8.33 & -1.66 & 16.52 & 11.05 & -8.87 & -1.09 & -34.62 & 29.26 & 24.76 \\
\hline MOHC-RCA4-45 & 93 & 64 & 72 & 53 & 45 & 6 & 25 & 52 & 92 & 75 & 73 & 52 \\
\hline Relative Difference (\%) & 40.3 & -8.83 & 3.88 & -23.31 & -42.4 & -88.48 & -39.35 & 41.02 & 86.09 & -6.17 & -15.74 & -48 \\
\hline MPI-R9-45 & 60 & 61 & 69 & 72 & 47 & 40 & 29 & 28 & 35 & 83 & 103 & 129 \\
\hline Relative Difference (\%) & -9.71 & -12.98 & -0.77 & 3.45 & -38.53 & -25.05 & -30.02 & -22.14 & -29.59 & 3.55 & 18.78 & 28.04 \\
\hline MPI-RCA4-45 & 62 & 53 & 72 & 66 & 48 & 39 & 37 & 31 & 52 & 99 & 95 & 108 \\
\hline Relative Difference (\%) & -6.31 & -23.78 & 3.58 & -4.97 & -38.16 & -27.61 & -10.9 & -14.92 & 5.45 & 24.07 & 9.85 & 7.71 \\
\hline CNRM-CCLM4-85 & 56 & 85 & 52 & 80 & 72 & 54 & 26 & 13 & 39 & 89 & 109 & 104 \\
\hline Relative Difference (\%) & -15.44 & 20.93 & -24.23 & 14.82 & -6.4 & 0.18 & -38 & -63.17 & -21.22 & 11.86 & 25.25 & 3.52 \\
\hline MPI-CCLM4-85 & 61 & 63 & 94 & 62 & 66 & 31 & 17 & 27 & 22 & 84 & 105 & 101 \\
\hline Relative Difference (\%) & -7.41 & -10.32 & 36.47 & -10.99 & -14.13 & -41.51 & -57.66 & -25.41 & -55.81 & 5.84 & 21.49 & 0.19 \\
\hline MPI-R9-85 & 58 & 59 & 82 & 58 & 61 & 31 & 26 & 38 & 37 & 75 & 95 & 110 \\
\hline Relative Difference (\%) & -12.01 & -15.16 & 18.92 & -16.61 & -21.58 & -42.39 & -38.17 & 4.28 & -24.94 & -6.62 & 9.78 & 9.55 \\
\hline MPI-RCA4-85 & 73 & 53 & 66 & 53 & 46 & 32 & 31 & 38 & 46 & 90 & 88 & 98 \\
\hline Relative Difference (\%) & 10.37 & -24.5 & -4.65 & -24.26 & -40.43 & -40.98 & -25.58 & 2.87 & -7.01 & 12.68 & 1.71 & -3.15 \\
\hline \multicolumn{13}{|l|}{ B } \\
\hline \multicolumn{13}{|l|}{ Temperature } \\
\hline 2019-2038 & $\mathrm{J}$ & $\mathbf{F}$ & $\mathbf{M}$ & $\mathbf{A}$ & $\mathbf{M}$ & J & J & A & $\mathbf{S}$ & 0 & $\mathbf{N}$ & D \\
\hline Control & 2.39 & 3.73 & 6.85 & 11.34 & 15.48 & 20.01 & 22.68 & 22.64 & 18.23 & 13.61 & 7.54 & 3.24 \\
\hline IPSL-WRF-45 & 3.05 & 5.15 & 8.16 & 12.66 & 16.07 & 20.91 & 23.79 & 23.61 & 19.79 & 14.31 & 7.91 & 4.84 \\
\hline Absolute Difference & 0.66 & 1.42 & 1.3 & 1.32 & 0.59 & 0.9 & 1.11 & 0.98 & 1.57 & 0.7 & 0.37 & 1.6 \\
\hline MOHC-RCA4-45 & 3.86 & 6.66 & 10.03 & 15.57 & 20.07 & 23.29 & 23.63 & 20.94 & 15.9 & 11.78 & 6.04 & 3.72 \\
\hline Absolute Difference & 1.47 & 2.93 & 3.17 & 4.23 & 4.59 & 3.28 & 0.95 & -1.7 & -2.33 & -1.83 & -1.49 & 0.47 \\
\hline MPI-R9-45 & 2.74 & 4.21 & 6.61 & 11.1 & 16.02 & 21.12 & 23.48 & 23.52 & 19.4 & 13.55 & 7.85 & 3.71 \\
\hline Absolute Difference & 0.35 & 0.48 & -0.24 & -0.25 & 0.54 & 1.12 & 0.8 & 0.88 & 1.17 & -0.06 & 0.32 & 0.47 \\
\hline MPI-RCA4-45 & 2.57 & 4.05 & 6.79 & 12 & 16.4 & 21.92 & 23.47 & 23.15 & 19.15 & 13.95 & 7.95 & 3.79 \\
\hline Absolute Difference & 0.18 & 0.33 & -0.06 & 0.66 & 0.92 & 1.91 & 0.79 & 0.52 & 0.92 & 0.34 & 0.41 & 0.54 \\
\hline CNRM-CCLM4-85 & 1.74 & 3.63 & 5.84 & 11.4 & 15.3 & 20.12 & 23.11 & 23.01 & 18.24 & 13.27 & 8.31 & 3.36 \\
\hline Absolute Difference & -0.65 & -0.1 & -1.01 & 0.06 & -0.18 & 0.11 & 0.43 & 0.37 & 0.01 & -0.34 & 0.77 & 0.12 \\
\hline MPI-CCLM4-85 & 1.59 & 1.79 & 6.33 & 10.22 & 15.65 & 20.4 & 23.21 & 23.58 & 17.88 & 13.96 & 6.5 & 2.11 \\
\hline Absolute Difference & -0.8 & -1.94 & -0.52 & -1.13 & 0.16 & 0.39 & 0.52 & 0.94 & -0.35 & 0.35 & -1.03 & -1.13 \\
\hline MPI-R9-85 & 1.82 & 3.19 & 7.19 & 10.92 & 15.74 & 20.94 & 23.81 & 24.06 & 18.61 & 14.39 & 7.35 & 2.39 \\
\hline Absolute Difference & -0.58 & -0.54 & 0.34 & -0.42 & 0.26 & 0.93 & 1.13 & 1.42 & 0.39 & 0.78 & -0.18 & -0.85 \\
\hline MPI-RCA4-85 & 1.55 & 2.54 & 6.28 & 11.16 & 16.21 & 21.06 & 23.78 & 23.76 & 18.65 & 14.31 & 7.16 & 2.67 \\
\hline Absolute Difference & -0.84 & -1.18 & -0.57 & -0.18 & 0.73 & 1.05 & 1.09 & 1.12 & 0.42 & 0.7 & -0.38 & -0.58 \\
\hline 2039-2058 & $\mathbf{J}$ & $\mathbf{F}$ & M & A & $\mathbf{M}$ & $\mathrm{J}$ & $\mathrm{J}$ & A & $\mathbf{S}$ & 0 & $\mathbf{N}$ & D \\
\hline Control & 2.39 & 3.73 & 6.85 & 11.34 & 15.48 & 20.01 & 22.68 & 22.64 & 18.23 & 13.61 & 7.54 & 3.24 \\
\hline IPSL-WRF-45 & 4.38 & 7.55 & 9.61 & 13.55 & 16.97 & 21.68 & 24.63 & 24.97 & 19.95 & 15.03 & 8.59 & 4.2 \\
\hline Absolute Difference & 1.99 & 3.82 & 2.75 & 2.2 & 1.49 & 1.67 & 1.95 & 2.33 & 1.72 & 1.42 & 1.05 & 0.96 \\
\hline MOHC-RCA4-45 & 4.24 & 6.83 & 10 & 16.38 & 20.87 & 24.11 & 24.56 & 21.81 & 16.46 & 12.45 & 6.17 & 3.51 \\
\hline Absolute Difference & 1.85 & 3.11 & 3.15 & 5.04 & 5.39 & 4.1 & 1.88 & -0.83 & -1.76 & -1.17 & -1.36 & 0.27 \\
\hline MPI-R9-45 & 3.16 & 4.51 & 7.62 & 11.46 & 16.03 & 21.51 & 24.26 & 24.87 & 19.38 & 14.36 & 8.15 & 3.61 \\
\hline
\end{tabular}




\begin{tabular}{|c|c|c|c|c|c|c|c|c|c|c|c|c|}
\hline Absolute Difference & 0.77 & 0.79 & 0.76 & 0.12 & 0.54 & 1.51 & 1.57 & 2.24 & 1.16 & 0.75 & 0.62 & 0.37 \\
\hline MPI-RCA4-45 & 3.45 & 4.27 & 7.74 & 12.18 & 16.86 & 22.49 & 24.67 & 24.67 & 19.52 & 14.54 & 8.44 & 4.11 \\
\hline Absolute Difference & 1.06 & 0.54 & 0.88 & 0.84 & 1.37 & 2.48 & 1.99 & 2.03 & 1.29 & 0.93 & 0.9 & 0.86 \\
\hline CNRM-CCLM4-85 & 3.44 & 4.38 & 7.7 & 11.22 & 15.65 & 20.46 & 23.55 & 23.07 & 17.93 & 13.74 & 8.51 & 4.16 \\
\hline Absolute Difference & 1.05 & 0.66 & 0.85 & -0.12 & 0.16 & 0.45 & 0.87 & 0.44 & -0.29 & 0.13 & 0.97 & 0.91 \\
\hline MPI-CCLM4-85 & 2.65 & 3.96 & 7.48 & 11.44 & 16.78 & 21.47 & 24.13 & 24.69 & 20.08 & 14.6 & 8.13 & 2.62 \\
\hline Absolute Difference & 0.26 & 0.23 & 0.63 & 0.1 & 1.29 & 1.46 & 1.45 & 2.06 & 1.86 & 0.99 & 0.59 & -0.63 \\
\hline MPI-R9-85 & 3.54 & 4.85 & 8.12 & 12.09 & 16.73 & 22.23 & 25.05 & 25.36 & 20.75 & 15.39 & 9.07 & 3.17 \\
\hline Absolute Difference & 1.15 & 1.13 & 1.26 & 0.75 & 1.24 & 2.23 & 2.37 & 2.72 & 2.53 & 1.78 & 1.54 & -0.08 \\
\hline MPI-RCA4-85 & 2.74 & 4.27 & 7.79 & 12.94 & 17.93 & 22.98 & 24.66 & 24.82 & 20.27 & 15.27 & 9.01 & 3.33 \\
\hline Absolute Difference & 0.35 & 0.54 & 0.93 & 1.6 & 2.45 & 2.98 & 1.97 & 2.18 & 2.05 & 1.66 & 1.47 & 0.09 \\
\hline $2059-2078$ & $\mathrm{~J}$ & $\mathbf{F}$ & $M$ & A & $\mathbf{M}$ & $\mathrm{J}$ & $\mathrm{J}$ & A & $\mathbf{S}$ & 0 & $\mathbf{N}$ & D \\
\hline Control & 2.39 & 3.73 & 6.85 & 11.34 & 15.48 & 20.01 & 22.68 & 22.64 & 18.23 & 13.61 & 7.54 & 3.24 \\
\hline IPSL-WRF-45 & 5.4 & 7.24 & 9.98 & 13.6 & 17.08 & 21.92 & 24.81 & 25.13 & 20.01 & 15.63 & 9.62 & 4.96 \\
\hline Absolute Difference & 3.01 & 3.51 & 3.13 & 2.26 & 1.6 & 1.92 & 2.13 & 2.5 & 1.78 & 2.02 & 2.09 & 1.72 \\
\hline MOHC-RCA4-45 & 5.19 & 7.67 & 10.62 & 17.12 & 21.35 & 24.66 & 25.01 & 22.7 & 17.31 & 13.28 & 7.14 & 4.55 \\
\hline Absolute Difference & 2.8 & 3.94 & 3.77 & 5.78 & 5.87 & 4.66 & 2.33 & 0.06 & -0.91 & -0.33 & -0.39 & 1.3 \\
\hline MPI-R9-45 & 2.9 & 4.03 & 7.75 & 11.61 & 16.71 & 21.76 & 24.91 & 25.06 & 19.72 & 14.52 & 8.36 & 3.97 \\
\hline Absolute Difference & 0.51 & 0.3 & 0.89 & 0.26 & 1.23 & 1.75 & 2.23 & 2.42 & 1.49 & 0.91 & 0.82 & 0.73 \\
\hline MPI-RCA4-45 & 3.14 & 4.03 & 7.65 & 12.31 & 17.48 & 21.97 & 24.81 & 24.83 & 19.3 & 14.42 & 8.47 & 4.55 \\
\hline Absolute Difference & 0.75 & 0.3 & 0.79 & 0.97 & 2 & 1.96 & 2.13 & 2.2 & 1.07 & 0.81 & 0.94 & 1.31 \\
\hline CNRM-CCLM4-85 & 4.04 & 4.96 & 8.56 & 12.39 & 16.8 & 20.95 & 25.16 & 24.86 & 19.42 & 14.82 & 9.16 & 5.76 \\
\hline Absolute Difference & 1.65 & 1.23 & 1.71 & 1.04 & 1.31 & 0.94 & 2.47 & 2.22 & 1.19 & 1.21 & 1.63 & 2.52 \\
\hline MPI-CCLM4-85 & 4.32 & 5.1 & 7.19 & 12.95 & 17.02 & 22.55 & 25.3 & 25.37 & 21.39 & 15.24 & 9.22 & 4.91 \\
\hline Absolute Difference & 1.93 & 1.37 & 0.34 & 1.61 & 1.53 & 2.55 & 2.62 & 2.73 & 3.16 & 1.63 & 1.68 & 1.66 \\
\hline MPI-R9-85 & 4.99 & 6.06 & 8.21 & 13.69 & 17.35 & 22.8 & 26.37 & 26.23 & 21.42 & 15.91 & 9.9 & 5.76 \\
\hline Absolute Difference & 2.6 & 2.34 & 1.36 & 2.35 & 1.87 & 2.79 & 3.69 & 3.59 & 3.19 & 2.3 & 2.37 & 2.52 \\
\hline MPI-RCA4-85 & 4.77 & 5.71 & 8.12 & 14.36 & 18.78 & 24.17 & 26.23 & 25.92 & 21.32 & 15.88 & 9.69 & 5.4 \\
\hline Absolute Difference & 2.38 & 1.98 & 1.27 & 3.02 & 3.3 & 4.17 & 3.55 & 3.29 & 3.09 & 2.27 & 2.16 & 2.15 \\
\hline
\end{tabular}


Table S5. Monthly changes in precipitation in $\mathrm{mm}(\mathrm{A})$ and temperature in ${ }^{\circ} \mathrm{C}(\mathrm{B})$

\begin{tabular}{|c|c|c|c|c|c|}
\hline \multicolumn{3}{|l|}{ Precipitation } & \multirow{2}{*}{$\begin{array}{l}2019-2038 \\
\text { Percent Change } \\
\end{array}$} & \multirow{2}{*}{$\begin{array}{l}2039-2058 \\
\text { Percent Change }\end{array}$} & \multirow{2}{*}{$\begin{array}{l}2059-2078 \\
\text { Percent Change } \\
\end{array}$} \\
\hline Name & Season & Reference & & & \\
\hline \multirow[t]{4}{*}{ IPSL-WRF-45 } & Winter & 236.91 & -9.99 & -5.2 & -4.17 \\
\hline & Spring & 215.98 & 12.03 & -7.84 & 0.47 \\
\hline & Summer & 131.29 & 9.41 & 0.87 & 7.73 \\
\hline & Autumn & 215.75 & -4.69 & 3.28 & -1.3 \\
\hline \multirow[t]{4}{*}{ MOHC-RCA4-45 } & Winter & 236.91 & 1.39 & -7.46 & -11.78 \\
\hline & Spring & 215.98 & -17.79 & -36.25 & -21.44 \\
\hline & Summer & 131.29 & -13.96 & -18.81 & -36.98 \\
\hline & Autumn & 215.75 & 24.1 & 43.1 & 11.03 \\
\hline \multirow[t]{4}{*}{ MPI-R9-45 } & Winter & 236.91 & -6.07 & -5.29 & 5.37 \\
\hline & Spring & 215.98 & 0.57 & 1.94 & -12.92 \\
\hline & Summer & 131.29 & -21.08 & -29.71 & -25.8 \\
\hline & Autumn & 215.75 & 2.86 & 9.94 & 2.11 \\
\hline \multirow[t]{4}{*}{ MPI-RCA4-45 } & Winter & 236.91 & -14.97 & -3.83 & -5.52 \\
\hline & Spring & 215.98 & -8.52 & -11.71 & -14.11 \\
\hline & Summer & 131.29 & -28.87 & -37.94 & -18.82 \\
\hline & Autumn & 215.75 & -8.72 & 16.98 & 14.11 \\
\hline \multirow[t]{4}{*}{ CNRM-CCLM4-85 } & Winter & 236.91 & -9.14 & -4.22 & 3.38 \\
\hline & Spring & 215.98 & -0.35 & -0.09 & -5.26 \\
\hline & Summer & 131.29 & -38.66 & -15.33 & -29.46 \\
\hline & Autumn & 215.75 & 12.53 & 12.74 & 9.69 \\
\hline \multirow[t]{4}{*}{ MPI-CCLM4-85 } & Winter & 236.91 & -11.28 & -5.73 & -5.04 \\
\hline & Spring & 215.98 & -2.75 & -13.13 & 3.06 \\
\hline & Summer & 131.29 & -21.83 & -46.83 & -42.1 \\
\hline & Autumn & 215.75 & -2.2 & -12.55 & -1.94 \\
\hline \multirow[t]{4}{*}{ MPI-R9-85 } & Winter & 236.91 & -2.12 & 2.3 & -3.78 \\
\hline & Spring & 215.98 & -3.65 & -9.95 & -7.03 \\
\hline & Summer & 131.29 & -20.97 & -24.52 & -28.07 \\
\hline & Autumn & 215.75 & -6.7 & 1.36 & -4.21 \\
\hline \multirow[t]{4}{*}{ MPI-RCA4-85 } & Winter & 236.91 & -8.13 & -9.6 & -5.69 \\
\hline & Spring & 215.98 & -13.06 & -24 & -23.77 \\
\hline & Summer & 131.29 & -2.95 & -12.91 & -23.93 \\
\hline & Autumn & 215.75 & -16.1 & 10.14 & 3.78 \\
\hline \multicolumn{6}{|l|}{ Temperature } \\
\hline Name & Season & Reference & Change & Change & Change \\
\hline \multirow{4}{*}{ IPSL-WRF-45 } & Winter & 3.12 & 1.23 & 2.26 & 2.75 \\
\hline & Spring & 11.23 & 1.07 & 2.15 & 2.33 \\
\hline & Summer & 21.77 & 1 & 1.98 & 2.18 \\
\hline & Autumn & 13.12 & 0.88 & 1.4 & 1.96 \\
\hline \multirow[t]{4}{*}{ MOHC-RCA4-45 } & Winter & 3.12 & 1.62 & 1.74 & 2.68 \\
\hline & Spring & 11.23 & 4 & 4.52 & 5.14 \\
\hline & Summer & 21.77 & 0.85 & 1.72 & 2.35 \\
\hline & Autumn & 13.12 & -1.89 & -1.43 & -0.55 \\
\hline MPI-R9-45 & Winter & 3.12 & 0.44 & 0.64 & 0.51 \\
\hline & Spring & 11.23 & 0.02 & 0.48 & 0.79 \\
\hline & Summer & 21.77 & 0.93 & 1.77 & 2.13 \\
\hline & Autumn & 13.12 & 0.48 & 0.84 & 1.07 \\
\hline MPI-RCA4-45 & Winter & 3.12 & 0.35 & 0.82 & 0.79 \\
\hline & Spring & 11.23 & 0.51 & 1.03 & 1.25 \\
\hline & Summer & 21.77 & 1.07 & 2.17 & 2.1 \\
\hline & Autumn & 13.12 & 0.56 & 1.04 & 0.94 \\
\hline CNRM-CCLM4-85 & Winter & 3.12 & -0.21 & 0.87 & 1.8 \\
\hline & Spring & 11.23 & -0.38 & 0.29 & 1.35 \\
\hline & Summer & 21.77 & 0.31 & 0.59 & 1.88 \\
\hline & Autumn & 13.12 & 0.15 & 0.27 & 1.34 \\
\hline MPI-CCLM4-85 & Winter & 3.12 & -1.29 & -0.05 & 1.66 \\
\hline & Spring & 11.23 & -0.49 & 0.67 & 1.16 \\
\hline & Summer & 21.77 & 0.62 & 1.66 & 2.63 \\
\hline & Autumn & 13.12 & -0.35 & 1.14 & 2.16 \\
\hline MPI-R9-85 & Winter & 3.12 & -0.65 & 0.73 & 2.48 \\
\hline & Spring & 11.23 & 0.06 & 1.08 & 1.86 \\
\hline
\end{tabular}




\begin{tabular}{|l|l|c|c|c|c|}
\hline & Summer & 21.77 & 1.16 & 2.44 & 3.36 \\
\cline { 2 - 6 } & Autumn & 13.12 & 0.33 & 1.95 & 2.62 \\
\hline \multirow{4}{*}{ MPI-RCA4-85 } & Winter & 3.12 & -0.87 & 0.33 & 2.17 \\
\cline { 2 - 6 } & Spring & 11.23 & -0.01 & 1.66 & 2.53 \\
\cline { 2 - 6 } & Summer & 21.77 & 1.09 & 2.38 & 3.67 \\
\cline { 2 - 6 } & Autumn & 13.12 & 0.25 & 1.73 & 2.5 \\
\hline
\end{tabular}


Table S6. Mean Annual Water balance components of Lake Oresteiada

\begin{tabular}{|c|c|c|c|c|c|c|c|c|c|c|c|c|c|c|c|}
\hline \multirow[b]{2}{*}{$\times 10^{6} \mathrm{~m}^{3}$} & \multicolumn{3}{|c|}{ Precipitation } & \multicolumn{3}{|c|}{ Evaporation } & \multicolumn{3}{|c|}{ Surface Flow } & \multicolumn{3}{|c|}{ Sub-Surface Flow } & \multicolumn{3}{|c|}{ Gkioli Outflow } \\
\hline & $\begin{array}{l}2019- \\
2038 \\
\end{array}$ & $\begin{array}{l}2039- \\
2058 \\
\end{array}$ & $\begin{array}{l}2059- \\
2078\end{array}$ & $\begin{array}{l}2019- \\
2038 \\
\end{array}$ & $\begin{array}{l}2039- \\
2058\end{array}$ & $\begin{array}{l}2059- \\
2078 \\
\end{array}$ & $\begin{array}{l}2019- \\
2038\end{array}$ & $\begin{array}{l}2039- \\
2058 \\
\end{array}$ & $\begin{array}{l}2059- \\
2078\end{array}$ & $\begin{array}{l}2019- \\
2038 \\
\end{array}$ & $\begin{array}{l}2039- \\
2058 \\
\end{array}$ & $\begin{array}{l}2059- \\
2078\end{array}$ & $\begin{array}{l}2019- \\
2038\end{array}$ & $\begin{array}{l}2039- \\
2058\end{array}$ & $\begin{array}{r}2059- \\
2078 \\
\end{array}$ \\
\hline Reference & 19.62 & 19.62 & 19.62 & 29.05 & 29.05 & 29.05 & 29.96 & 29.96 & 29.96 & 36.16 & 36.16 & 36.16 & 55.96 & 55.96 & 55.96 \\
\hline IPSL-WRF-45 & 19.03 & 17.56 & 18.69 & 32.39 & 33.78 & 33.58 & 35.33 & 32.88 & 34.54 & 37.35 & 35.42 & 36.75 & 59.33 & 52.08 & 56.40 \\
\hline Difference & -0.58 & -2.06 & -0.92 & 3.34 & 4.73 & 4.53 & 5.37 & 2.92 & 4.58 & 1.19 & -0.74 & 0.59 & 3.37 & -3.88 & 0.45 \\
\hline $\begin{array}{c}\text { Relative Difference } \\
(\%)\end{array}$ & -2.96 & -10.50 & -4.70 & 11.51 & 16.29 & 15.60 & 17.92 & 9.73 & 15.28 & 3.30 & -2.05 & 1.62 & 6.03 & -6.93 & 0.80 \\
\hline MOHC-RCA4-45 & 15.31 & 13.68 & 12.91 & 34.26 & 35.03 & 35.91 & 31.92 & 28.12 & 27.00 & 35.78 & 31.72 & 30.99 & 48.74 & 38.49 & 34.99 \\
\hline Difference & -4.31 & -5.93 & -6.71 & 5.22 & 5.98 & 6.86 & 1.96 & -1.84 & -2.96 & -0.38 & -4.44 & -5.17 & -7.21 & -17.46 & -20.96 \\
\hline $\begin{array}{l}\text { Relative Difference } \\
(\%)\end{array}$ & -21.96 & -30.25 & -34.18 & 17.95 & 20.58 & 23.62 & 6.55 & -6.15 & -9.88 & -1.06 & -12.29 & -14.30 & -12.89 & -31.21 & -37.47 \\
\hline MPI-R9-45 & 16.52 & 15.92 & 16.12 & 32.76 & 33.59 & 33.88 & 30.86 & 30.21 & 30.25 & 35.28 & 35.60 & 36.08 & 49.89 & 48.14 & 48.58 \\
\hline Difference & -3.10 & -3.70 & -3.49 & 3.71 & 4.55 & 4.83 & 0.90 & 0.25 & 0.29 & -0.88 & -0.56 & -0.08 & -6.06 & -7.82 & -7.38 \\
\hline $\begin{array}{c}\text { Relative Difference } \\
(\%)\end{array}$ & -15.81 & -18.84 & -17.81 & 12.77 & 15.65 & 16.62 & 2.99 & 0.84 & 0.97 & -2.44 & -1.55 & -0.22 & -10.84 & -13.97 & -13.19 \\
\hline MPI-RCA4-45 & 14.67 & 14.52 & 15.78 & 32.80 & 33.79 & 33.54 & 28.24 & 28.10 & 29.81 & 35.90 & 33.40 & 37.12 & 46.01 & 42.23 & 49.17 \\
\hline Difference & -4.95 & -5.10 & -3.84 & 3.75 & 4.74 & 4.49 & -1.72 & -1.86 & -0.15 & -0.26 & -2.76 & 0.96 & -9.95 & -13.72 & -6.78 \\
\hline $\begin{array}{l}\text { Relative Difference } \\
(\%)\end{array}$ & -25.21 & -25.98 & -19.56 & 12.91 & 16.31 & 15.47 & -5.75 & -6.21 & -0.49 & -0.72 & -7.63 & 2.66 & -17.78 & -24.52 & -12.12 \\
\hline CNRM-CCLM4-85 & 15.05 & 17.01 & 16.25 & 32.22 & 32.31 & 33.55 & 28.28 & 31.71 & 30.32 & 33.52 & 32.42 & 36.30 & 44.62 & 48.84 & 49.32 \\
\hline Difference & -4.57 & -2.60 & -3.37 & 3.17 & 3.26 & 4.50 & -1.68 & 1.75 & 0.36 & -2.64 & -3.74 & 0.14 & -11.34 & -7.12 & -6.63 \\
\hline $\begin{array}{c}\text { Relative Difference } \\
(\%)\end{array}$ & -23.29 & -13.28 & -17.17 & 10.93 & 11.22 & 15.49 & -5.61 & 5.85 & 1.21 & -7.31 & -10.35 & 0.39 & -20.26 & -12.72 & -11.85 \\
\hline MPI-CCLM4-85 & 15.84 & 13.93 & 15.23 & 32.14 & 33.35 & 34.24 & 29.94 & 26.43 & 28.72 & 36.23 & 36.84 & 31.68 & 49.87 & 43.84 & 41.38 \\
\hline Difference & -3.78 & -5.69 & -4.38 & 3.09 & 4.30 & 5.19 & -0.02 & -3.53 & -1.24 & 0.07 & 0.68 & -4.48 & -6.08 & -12.11 & -14.57 \\
\hline $\begin{array}{c}\text { Relative Difference } \\
(\%)\end{array}$ & -19.27 & -28.99 & -22.34 & 10.64 & 14.82 & 17.88 & -0.06 & -11.79 & -4.15 & 0.20 & 1.87 & -12.40 & -10.87 & -21.65 & -26.04 \\
\hline MPI-R9-85 & 16.37 & 16.11 & 15.64 & 32.97 & 34.13 & 35.12 & 31.00 & 30.42 & 29.62 & 34.78 & 35.61 & 36.11 & 49.18 & 48.01 & 46.25 \\
\hline Difference & -3.25 & -3.50 & -3.98 & 3.92 & 5.08 & 6.07 & 1.04 & 0.46 & -0.35 & -1.38 & -0.55 & -0.05 & -6.78 & -7.94 & -9.71 \\
\hline $\begin{array}{c}\text { Relative Difference } \\
(\%)\end{array}$ & -16.56 & -17.86 & -20.27 & 13.51 & 17.49 & 20.90 & 3.48 & 1.53 & -1.15 & -3.82 & -1.52 & -0.14 & -12.11 & -14.19 & -17.35 \\
\hline MPI-RCA4-85 & 16.67 & 15.57 & 14.86 & 32.56 & 33.89 & 35.08 & 31.62 & 28.89 & 28.17 & 33.80 & 32.40 & 31.66 & 49.52 & 42.97 & 39.62 \\
\hline Difference & -2.95 & -4.04 & -4.76 & 3.52 & 4.84 & 6.03 & 1.66 & -1.07 & -1.79 & -2.36 & -3.77 & -4.50 & -6.44 & -12.99 & -16.34 \\
\hline $\begin{array}{c}\text { Relative Difference } \\
(\%)\end{array}$ & -15.04 & -20.61 & -24.27 & 12.10 & 16.67 & 20.75 & 5.54 & -3.58 & -5.96 & -11.50 & -23.21 & -29.20 & -5.56 & -18.05 & -24.44 \\
\hline
\end{tabular}


Figure S1. Simulation area of FeFLOW model, assigned boundary conditions, including public irrigation network boreholes

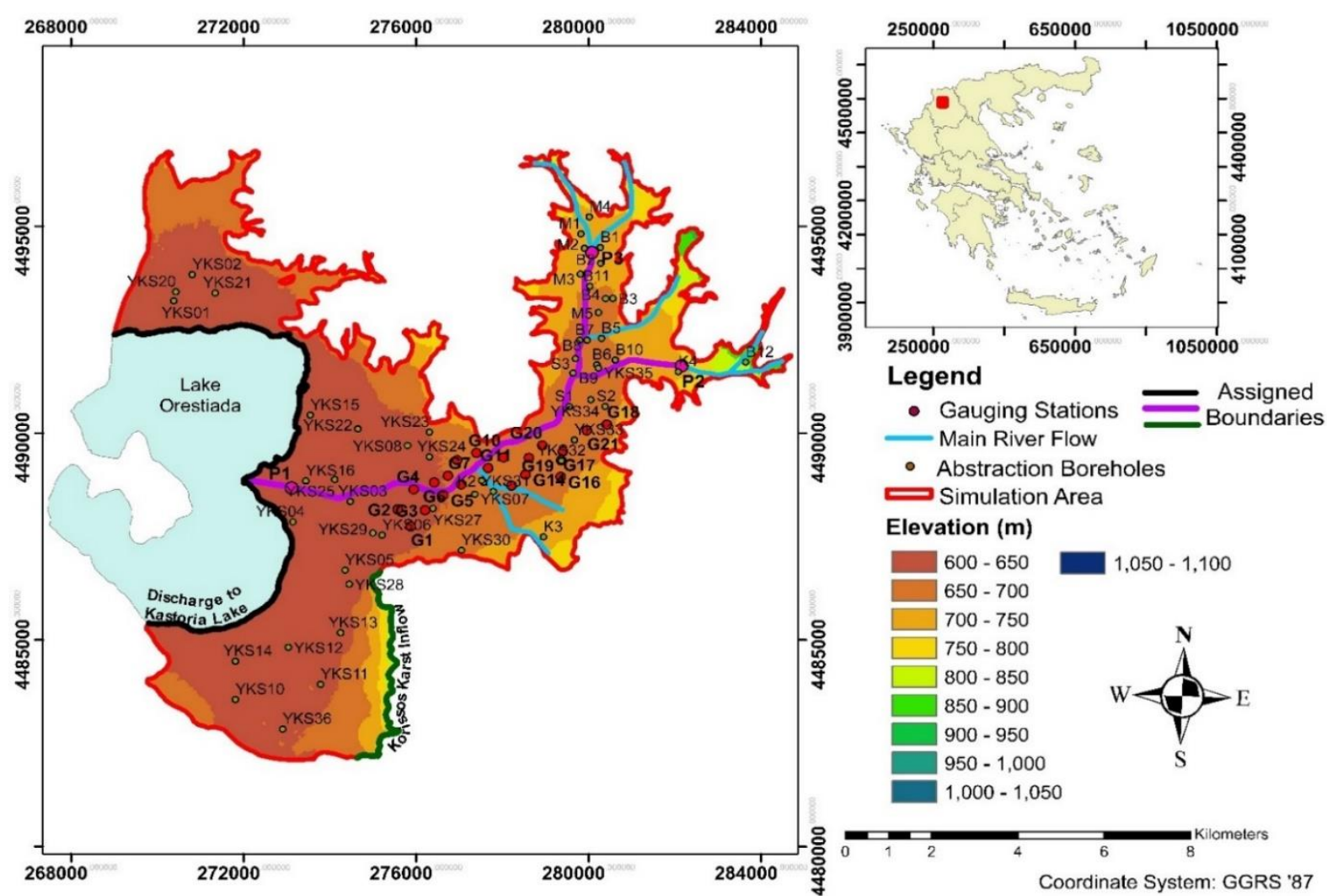

